Portland State University

PDXScholar

3-2009

\title{
Preliminary Characterization of Mitochondrial ATP- sensitive Potassium Channel (MitoKATP) Activity in Mouse Heart Mitochondria
}

Venkat Raghav Aachi

Portland State University

Follow this and additional works at: https://pdxscholar.library.pdx.edu/open_access_etds

Part of the Biology Commons, and the Cardiovascular Diseases Commons Let us know how access to this document benefits you.

Recommended Citation

Aachi, Venkat Raghav, "Preliminary Characterization of Mitochondrial ATP-sensitive Potassium Channel (MitoKATP) Activity in Mouse Heart Mitochondria" (2009). Dissertations and Theses. Paper 1667.

https://doi.org/10.15760/etd.1666

This Thesis is brought to you for free and open access. It has been accepted for inclusion in Dissertations and Theses by an authorized administrator of PDXScholar. Please contact us if we can make this document more accessible: pdxscholar@pdx.edu. 


\section{THESIS APPROVAL}

The abstract and thesis of Venkat Raghav Aachi for the Master of Science in Biology were presented March 13, 2009, and accepted by the thesis committee and the department.

COMMITTEE APPROVALS:

DEPARTMENT APPROVAL:

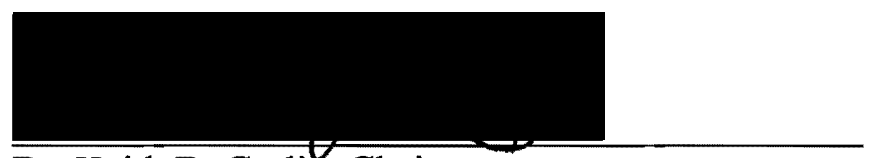

Dr. Keith D. Garlid, Chair

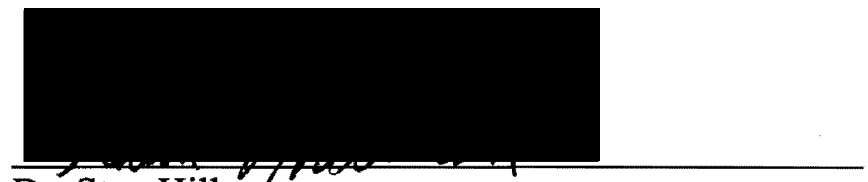

Dr. Stan Hillman

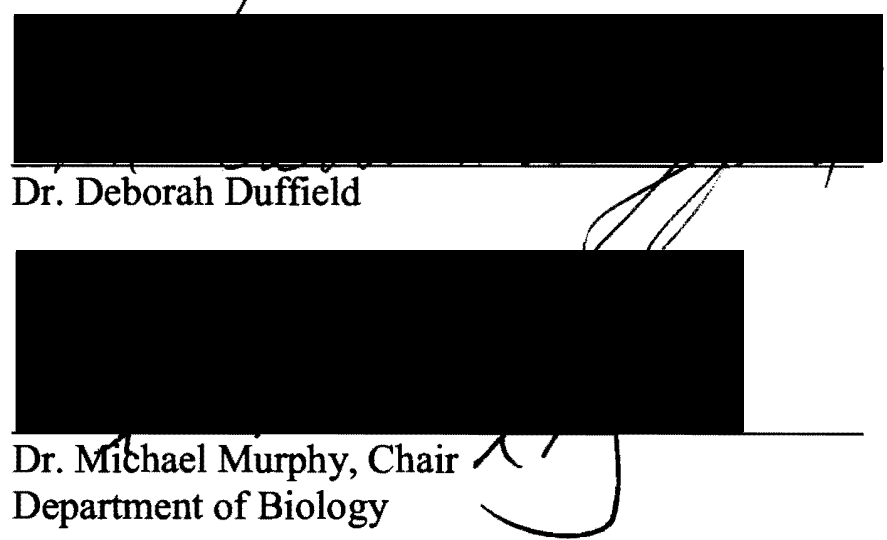




\begin{abstract}
An abstract of the thesis of Venkat Raghav Aachi for the Master of Science in Biology presented March 13, 2009.
\end{abstract}

Title: Preliminary characterization of Mitochondrial ATP-sensitive potassium channel (MitoKATP) activity in mouse heart mitochondria.

Myocardial ischemia, infarction, heart failure and arrhythmias are the manifestations of coronary artery disease. Reduction of ischemic damage is a major concern of cardiovascular biology research. As per recent studies, the mitochondrial ATP-sensitive potassium channel (mitoK $\mathrm{KTP}_{\mathrm{AT}}$ ) opening is believed to play a key role in the physiology of cardioprotection, protection against ischemia-reperfusion injury or apoptosis. However, the structural information of mitoK $\mathrm{ATP}_{\mathrm{A}}$ is not precisely known. Elucidating the structural integrity and functioning of the mitoK $\mathrm{ATP}_{\mathrm{AT}}$ is therefore a major goal of cardiovascular biology research. The known structure and function of the cell ATP-sensitive potassium channel $\left(\right.$ cellK $\left.\mathrm{K}_{\mathrm{ATP}}\right)$ is functional in interpreting the structural and functional properties of mitoK $\mathrm{K}_{\mathrm{ATP}}$.

The primary goal of my research was to characterize the activity of mitoK $\mathrm{ATP}_{\mathrm{P}}$ in the isolated mitochondria from the control mouse heart. The mitoK $\mathrm{ATP}_{\mathrm{Activity}}$ if preliminarily characterized in the control strains through the light scattering technique, then the structure of the channel could possibly be established and analyzed by means 
of the transgenic model and with the help of immunological techniques such as western blotting and immunoflorescence.

With this experimental model it was possible to demonstrate that the mito $\mathrm{K}_{\text {ATP }}$ activity in control mouse heart mitochondria is activated by potassium channel openers (KCOs) such as diazoxide and cromakalim and activators of mito $\mathrm{K}_{\mathrm{ATP}}$ such as PMA (phorbol 12 myristate-13-acetate), and inhibited by $\mathrm{K}_{\mathrm{ATP}}$ inhibitors such as glibenclamide and 5-hydroxydecanoate (5 HD).

It was evident that the mitoK $\mathrm{ATP}_{\mathrm{ATP}}$ activity in mouse heart mitochondria was comparable to that exhibited by the rat heart mitochondria. The various selective and non-selective activators and inhibitors of the channel elicited their activity at a similar concentration used for the rat heart mitochondria. The results were reproducible in five independent experiments for each combination, further reinforcing the significance of existing channel activity in the mouse heart mitochondria. 


\title{
PRELIMINARY CHARACTERIZATION OF MITOCHONDRIAL ATP- SENSITIVE POTASSIUM CHANNEL (MITOKATP) ACTIVITY IN MOUSE HEART MITOCHONDRIA
}

\author{
by \\ VENKAT RAGHAV AACHI
}

\begin{abstract}
A thesis submitted in partial fulfillment of the requirements for the degree of

\section{MASTER OF SCIENCE \\ in \\ BIOLOGY}

Portland State University

2009 


\section{DEDICATION}

My work is dedicated to my parents, my brother and to all my friends 


\section{ACKNOWLEDGEMENTS}

I would like to thank my advisor, Dr. Keith D. Garlid, for being truly supportive of my work throughout my tenure as a graduate student. I am thoroughly indebted to Dr. Garlid for having introduced me to the world of clinical research, which I am sure, has helped me grow as a clinician in specific, and a person in general.

I am extremely grateful to Dr. Stan Hillman and Dr. Debbie Duffield, for having agreed to be on my committee, and helping me out with their careful evaluation of my work and valuable comments.

I would like to thank Dr. Alex D. Costa, who taught me the intricacies of the various experimental procedures, and guided me throughout the project with his technical expertise.

My heartfelt thanks to Craig Semrad, for his tremendous support, technical advice and cooperation.

I greatly appreciate the friendship and support of Casey, Abraham, Cynthia, Beau, Ksenia, Nastia and other members of Dr. Garlid's lab.

I sincerely thank Dr. Michael Murphy and Dr. Suzanne Estess, for helping me out with my graduation process.

Finally, I would want to thank my family and friends, without whom this journey would not have been this worthwhile. 
TABLE OF CONTENTS:

ACKNOWLEDGEMENTS

LIST OF TABLES vi vi

LIST OF FIGURES vii

ABBREVIATIONS $\quad$ ix

$\begin{array}{lll}\text { CHAPTER 1: } & \text { INTRODUCTION }\end{array}$

1.1 Rationale for mouse as the study model 2

CHAPTER 2: $\quad$ ATP-SENSITIVE POTASSIUM CHANNELS $\quad 4$

2.1 Plasma Membrane / Sarcolemmal $\mathrm{K}_{\mathrm{ATP}}$ Channels (CellK $\left.\mathrm{ATP}_{\mathrm{AT}}\right) \quad 4$

2.2 Physiological roles of cellK $\mathrm{KTP} \quad 5$

2.3 Pharmacological directive of cellK ATP $\quad 5$

$\begin{array}{lll}2.4 & \text { Structure of cellK } \\ \text { ATP } & 7\end{array}$

2.5 Mitochondrial $\mathrm{K}_{\mathrm{ATP}}$ Channels (MitoK ATP $) \quad 9$

$\begin{array}{lll}2.6 & \text { Regulation of matrix volume by } \text { MitoK }_{\mathrm{ATP}} & 10\end{array}$

$\begin{array}{lll}2.7 & \text { Oxidative phosphorylation } & 11\end{array}$

2.8 Myocardial Ischemia and cardioprotection $\quad 11$ 
2.9 MitoK $_{\text {ATP }}$ as a receptor for KCOs and their inhibitors

2.10 Sulfonylurea receptor of mitoK $\mathrm{K}_{\mathrm{ATP}}$

2.11 Kir subunit of mitoK ATP $_{\text {A }}$

CHAPTER 3: $\quad$ MATERIALS AND METHODS

3.1 Mitochondrial isolation

3.2 Assay Medium

3.3 Measurement of mitochondrial volume

3.4 Chemicals

20

CHAPTER 4: $\quad \mathrm{K}_{\text {ATP }}$ CHANNEL OPENERS AND BLOCKERS

4.1 Non-selective $\mathrm{K}_{\mathrm{ATP}}$ agonists

4.2 Selective mitoK $\mathrm{K}_{\mathrm{ATP}}$ agonists

22

4.3 $\mathrm{K}_{\text {ATP }}$ channel blockers

22

CHAPTER 5: $\quad$ RESULTS

5.1 Mechanism of activation of mitoK $\mathrm{K}_{\mathrm{ATP}}$ by PMA

CHAPTER 6: DISCUSSION 


\section{LIST OF TABLES}

Table 1: Pharmacological agents currently under investigation.......... 


\section{LIST OF FIGURES:}

Figure 1: Mitochondrial Potassium cycle......................... 30

Figure 2: Proposed interaction of regulatory ligands with mitoK $\mathrm{ATP}_{\mathrm{A}} \ldots .$.

Figure 3: Intramitochondrial Signaling pathway

Figure 4: Light scattering traces showing 5-HD inhibiting Diazoxide

in mouse heart mitochondria.

Figure 5: Light scattering traces showing Glibenclamide inhibiting

Diazoxide in mouse heart mitochondria.

Figure 6: Light scattering traces showing 5-HD inhibiting Cromakalim

in mouse heart mitochondria.

Figure 7: Light scattering traces showing Glibenclamide inhibiting

Cromakalim in mouse heart mitochondria

Figure 8: Light scattering traces showing Glibenclamide inhibiting

PMA in mouse heart mitochondria.................................

Figure 9: Light scattering traces showing 5-HD inhibiting PMA

in mouse heart mitochondria. 
Figure 10: Summarized data for the percentage mitoK $\mathrm{ATP}_{\mathrm{Activity}}$ exhibited by diazoxide and blockers 5 hydroxydecanoate ( $5 \mathrm{HD})$ and

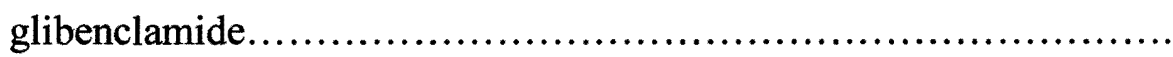

Figure 11: Summarized data for the percentage mitoK $_{\mathrm{ATP}}$ activity exhibited by cromakalim and blockers 5 hydroxydecanoate ( $5 \mathrm{HD}$ ) and

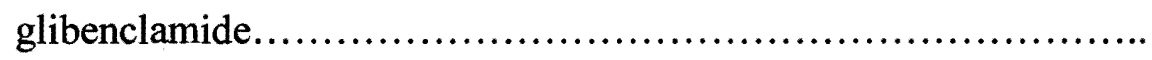

Figure 12: Summarized data for the percentage mitoK $_{\text {ATP }}$ activity exhibited by PMA and blockers 5 hydroxydecanoate $(5 \mathrm{HD})$ and

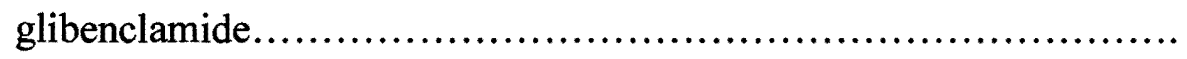

Figure 13: Light scattering traces showing mitoK $_{\text {ATP }}$ activity in rat

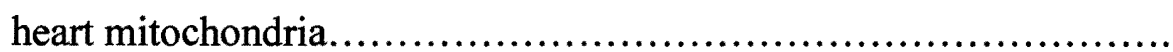

Figure 14: Comparing the $\%$ mitoK $_{\text {ATP }}$ in rat vs. mouse heart... 


\section{ABBREVIATIONS}

ADP

ATP

APD

$\mathrm{ATP}_{\mathrm{i}}$

BLM

BSA

CellK $_{\text {ATP }}$

CoA

CRM

DAG

DEAE-cellulose

DZX

DMSO

EDTA

EGTA

eNOS

FA

$\mathrm{FADH}_{2}$

FL-glyburide

GDP
Adenosine diphosphate

Adenosine triphosphate

Action potential duration

Intracellular ATP

bilayer lipid membrane

bovine serum albumin

plasma membrane $\mathrm{K}_{\mathrm{ATP}}$ channel

coenzyme A

cromakalim

diacylglycerol

diethylaminoethyl-cellulose

diazoxide

Dimethyl Sulfoxide

ethylene diamine tetraacetic acid

ethylene glycol tetraacetic acid

endothelial nitric oxide synthase

fatty acid

reduced flavin adenine dinucleotide

BODIPY FL glibenclamide

guanosine diphosphate

ix 
GTP

GLI

5-HD

HEPES

$\mathrm{IP}_{3}$

$\mathrm{KCO}$

$\mathrm{Kir}$

MitoK $_{\text {ATP }}$

MPT

$\mathrm{NADH}$

NBF

PAGE

PKC

PMA

PKG

$\mathrm{Pi}$

PLC

$\mathrm{PIP}_{2}$

SDS

SUR

TEA

$\mathrm{TPP}^{+}$ guanosine triphosphate

glibenclamide

5-hydroxydecanoate

4-(2-hydroxyethyl)-1-piperazineethanesulfonic acid

inositol 1, 3, 4 triphosphate

potassium channel opener

inward rectifying potassium channel

mitochondrial $\mathrm{K}_{\mathrm{ATP}}$ channel

mitochondrial permeability transition

$\alpha$-nicotinamide-adenine dinucleotide

nucleotide binding fold

polyacrylamide gel electrophoresis

protein kinase $\mathrm{C}$

phorbol 12 myristate-13-acetate

protein kinase $\mathrm{G}$

phosphate

phospholipase C

phosphatidyl inositol 4, 5 bisphosphate

sodium dodecyl sulfate

sulfonylurea receptor

tetraethylammonium cation

tetraphenylphosphonium ion 
$\mathrm{W}_{\mathrm{A}}$

$\mathrm{W}_{\mathrm{B}}$
Walker A motif

Walker B motif 


\section{CHAPTER 1}

\section{INTRODUCTION}

Cardiovascular disease can manifest as acute myocardial infarction, myocardial ischemia or arrhythmias $[72,75,84]$. Myocardial ischemia, as defined, is a reduction in the blood supply to the heart muscle owing to the constriction or obstruction of the coronary arteries. The lack of blood supply to the heart leads to a reduction in the oxygen supply to the contractile heart muscle and eventual accumulation of toxic metabolites, leading to a permanent damage to the heart tissue. The irreversible necrosis of the heart tissue owing to the compromised blood supply manifests as infarction. The infarcted heart tissue loses the power to regenerate and subsequently ends up with a compromised ventricular function. [72, 75, 84]

Reducing the morbidity and improving the clinical outcome in patients with coronary artery disease is a major concern of cardiovascular biology research. The mitochondrial ATP-sensitive potassium channel ( mitoK $\left._{\mathrm{ATP}}\right)$ is thought to have a significant effect in the physiology of ischemic signaling pathway, protecting the myocardium against the ischemia-reperfusion injury (considering the reduction in the size of infarct when subjected to mitoK $_{\mathrm{ATP}}$ specific potassium channel openers during ischemic preconditioning; an effect reversed in the presence of potassium channel blockers) $[46,47]$. It is therefore important to address questions regarding the 
structural and functional properties of mitoK $_{\mathrm{ATP}}$ to further delineate its role in health and disease.

\subsection{Rationale for mouse as the study model:}

Mice are probably the only mammalian species that are subjected to routine genetic manipulations. Also, the mouse genome is one of the most extensively studied genomes. The structural subunit assembly of mitoK $\mathrm{K}_{\mathrm{ATP}}$ is quite unclear. It is still a matter of ambiguity what channel subunits constitute the mitoK $\mathrm{K}_{\mathrm{ATP}}$.

Through my study I intended to preliminarily characterize the mitoK $_{\text {ATP }}$ activity in control mouse heart mitochondria. I believe that the mitoK $_{\mathrm{ATP}}$ activity if successfully characterized in the control mouse strains would eventually facilitate in understanding the structural constitution and assembly of the channel subunits through the study model of transgenic mice and various immunological techniques. Also, I intended to test the hypothesis that the mitoK $\mathrm{ATP}_{\mathrm{AT}}$ activity exhibited in control mouse heart mitochondria is similar and comparable to that exhibited in rat heart mitochondria.

The structure of mitoK $\mathrm{K}_{\mathrm{ATP}}$ could be understood in much detail by pursuing the model of genetically modified mice (transgenic mice) with their cellK $\mathrm{K}_{\mathrm{ATP}}$ channel subunits over-expressed or knocked-out. Performing light scattering experiments on the isolated heart mitochondria from the transgenic mouse model, and by subjecting the isolated mitochondria to various selective and non selective $\mathrm{KCO}$ and blockers, 
would eventually facilitate in characterization of the mitoK $\mathrm{K}_{\mathrm{ATP}}$ activity in these study models. The structural subunits constituting the mitoK $_{\text {ATP }}$ could be analyzed through various immunological techniques such as western blotting and immunoflorescence. 


\section{CHAPTER 2}

\section{ATP-SENSITIVE POTASSIUM CHANNELS (K ATP $)$}

There are two types of $\mathrm{K}_{\mathrm{ATP}}$ channels constituting the cardiac myocyte. These include, the cellK $\mathrm{K}_{\mathrm{ATP}}$ channel / sarcolemmalK $\mathrm{ATP}_{\mathrm{AT}}$ channel in the plasma membrane, and the mitochondrial $\mathrm{K}_{\mathrm{ATP}}\left(\right.$ mitoK $\left._{\mathrm{ATP}}\right)$ in the inner membrane of the mitochondria $[1,44,77$, 82].

\subsection{Plasma Membrane / Sarcolemmal $K_{\text {ATP }}$ Channels (CellK $\left.{ }_{\text {ATP }}\right)$}

The potassium channels form the prime component of plasma membrane of cells of various tissues [1-6]. The potassium channels function in setting up a resting membrane potential, regulating the electrical activity and ion transport across the membrane. The ATP-sensitive potassium channels $\left(\mathrm{K}_{\mathrm{ATP}}\right)$ were first identified in the plasma membrane of cardiac myocyte by Noma through his experiments using single channel patch clamp techniques [1]. CellK $\mathrm{ATP}_{\mathrm{AP}}$ are expressed in diverse tissues of the body that include pancreatic $\beta$ cells, skeletal muscle, smooth muscle and neurons of the brain parenchyma, in addition to the cardiac cells. $[2,3,4,5,6]$

The cell ATP-sensitive potassium channels are involved in a variety of regulatory functions that include shortening of the action potential duration in cardiac myofibrils, loss of $\mathrm{K}^{+}$ions during functional inhibition in heart, regulation of the skeletal muscle 
excitation, pancreatic $\beta$-cell release of insulin, relaxation of smooth muscle and the release of various neurotransmitters from the neurons of brain parenchyma $[7,8,9]$.

\subsection{Physiological roles of CellK $\mathrm{ATP}_{\mathrm{A}}$}

The opening of the cell $\mathrm{K}_{\mathrm{ATP}}$ leads to hyperpolarization of the cell plasma membrane. Hyperpolarization of the pancreatic $\beta$-cells inhibits glucose-stimulated insulin secretion by preventing the increase in intracellular $\mathrm{Ca}^{+2}$. Depolarizing the plasma membrane of the pancreatic $\beta$-cells leads to opening of voltage gated $\mathrm{Ca}^{+2}$ channels, elevation of intracellular $\mathrm{Ca}^{+2}$ and eventual exocytosis of insulin granules [10]. In the myocardium, excess efflux of $\mathrm{K}^{+}$leads to a reduced influx of $\mathrm{Ca}^{+2}$ by decreasing the action potential duration. This reduced intracellular $\mathrm{Ca}^{+2}$ results in a reduction in the contractility of the heart and possible rhythm disturbances during ischemia [11, 12]. The cell $\mathrm{K}_{\mathrm{ATP}}$ opening in the arteriolar smooth muscles results in a reduction in blood pressure, primarily mediated through a fall in the arteriolar resistance [13].

\subsection{Pharmacological directive of cellK $\mathrm{ATP}_{\mathrm{AT}}$}

Intracellular ATP $\left(\mathrm{ATP}_{\mathrm{i}}\right)$ and ADP primarily regulate the activity of the cellK $\mathrm{ATP}_{\mathrm{ATP}}$ [4]. $\operatorname{ATP}_{\mathrm{i}}$ is functional in closing the channel and maintains the channel activity in the presence of $\mathrm{Mg}^{+2}$ [14-17]. Under normal physiological concentrations of $\mathrm{ATP}_{\mathrm{i}}$, the probability of cellK $\mathrm{K}_{\mathrm{ATP}}$ to be in an open state is minimal. The $\mathrm{ATP}_{\mathrm{i}}$ is viewed to be bound to the cell $\mathrm{K}_{\mathrm{ATP}}$, for the channel to remain in the closed state. Hydrolysis of ATP 
in the presence of $\mathrm{Mg}^{+2}$ emphasizes the pivotal role of protein phosphorylation in maintaining the channel activity [7].

The ATP inhibition of $\mathrm{K}_{\mathrm{ATP}}$ channels is reversed by a class of drugs called potassium channel openers (KCOs) that include cromakalim, diazoxide, minoxidil, pinacidil and nicorandil. The properties of $\mathrm{K}_{\mathrm{ATP}}$ channels vary among tissues. For example pinacidil activates cardiac cellK $\mathrm{K}_{\mathrm{ATP}}$ but diazoxide does not; the pancreatic $\beta$-cell $\mathrm{K}_{\mathrm{ATP}}$ activity is weak in the presence of pinacidil, but shows significant activity with diazoxide. Both diazoxide and pinacidil effectively activate smooth muscle cellK $\mathrm{K}_{\mathrm{ATP}}$ resulting in vasodilatation $[7,21,22]$. The differential activities exhibited by cell $\mathrm{K}_{\mathrm{ATP}}$ lead to the assertion that there are receptor subtypes among cellK $\mathrm{K}_{\mathrm{ATP}}[21,22]$

Glyburide and glibenclamide, which belong to the sulfonylurea class of anti-diabetic drugs, have also been found to block the activity of $\mathrm{K}_{\mathrm{ATP}}$. Inhibition of $\mathrm{K}_{\mathrm{ATP}}$ channel in the pancreatic $\beta$-cells leads to a series of events that eventually result in the release of insulin, and hence sometimes referred to as insulin secretagogues considering their pro-insulin action $[3,24,25]$. Their action on the cardiac and smooth muscle cells requires higher concentrations than in the pancreatic $\beta$-cells [23]. Glyburide and glibenclamide are not really indicated in patients susceptible to ischemia, as they have been found to reverse the cardioprotective effects of the KCOs and result in rhythm disturbances $[13,19]$. The inhibition of $\mathrm{K}_{\mathrm{ATP}}$ by ATP is independent of phosphorylation and the sensitivity of $\mathrm{K}_{\mathrm{ATP}}$ channel to ATP is reduced in the presence 
of ADP [70]. Glyburide and Glibenclamide are classified as non-specific $\mathrm{K}_{\mathrm{ATP}}$ channel antagonists, considering their inhibitory action on the cell $\mathrm{K}_{\mathrm{ATP}}$ and the mitoK $\mathrm{K}_{\mathrm{ATP}}$. (Table1)

\subsection{Structure of cellK $\mathrm{K}_{\text {ATP }}$}

The complex of two different protein subunits namely, the inward-rectifying potassium channels (Kir) and the sulfonylurea receptor (SUR), form the cellK $\mathrm{ATP}_{\mathrm{AT}}$ [28]. The Kir can exist either as Kir6.1 or Kir6.2 $[18,27]$ and the SUR can exist as SUR1, SUR2A or SUR2B [29-31]. The regulatory SUR belongs to the ATP-binding cassette transporter family $(\mathrm{ABC})[32,33,72,77]$. The Kir subunit acts as a potassium conducting pore. The SUR subunit primarily regulates cellK $\mathrm{K}_{\mathrm{ATP}}$ activity $[29,30,72$, 77].

The complementarity-determining DNA (cDNA) that encoded for Kir6.1 was initially isolated from the pancreatic islet cDNA library of the rat [25]. The composition of rat Kir6.1 primarily included two transmembrane domains with a 424-amino acid residue protein $\left(M_{r}=47,960\right)$. The Kir6.2 fragment was isolated by means of the Kir6.1 as the probe for screening the human genomic library [34]. The Kir6.1 was almost 70\% identical to the Kir6.2 as revealed by the amino acid sequences $[34,35]$. The truncated form of Kir6.2 (with the last 26 or 36 amino acids deleted), when expressed in the absence of SUR, is found to be insensate to sulfonylureas, diazoxide, cromakalim and $\operatorname{Mg}-\operatorname{ADP}[18,36]$. 
SUR1 was recognized by means of radiolabeled analogs of glyburide. They were isolated in pancreatic $\beta$-cells as a $140 \mathrm{kD}$ protein on SDS-Polyacrylamide gel electrophoresis [26, 37]. Molecular cloning of SUR1 exposed that it encoded proteins of 1582 amino acids with 13 transmembrane domains and two nucleotide-binding folds (NBF) [31].

The cellK $\mathrm{KTP}_{\mathrm{AT}}$ from the pancreatic $\beta$-cells co-express SUR1 and Kir6.2 [34]. Mutations in NBF1 and NBF2 are viewed as functional in the pathophysiology of familial hyperinsulinemic hypoglycemia of infancy $[38,39]$. Walker $A\left(W_{A}\right)$ motifs of NBF1 and NBF2 are thought to be prospective sites of Mg-ADP activation of cell $\mathrm{K}_{\mathrm{ATP}}$ [40]. The activation of $\mathrm{K}_{\mathrm{ATP}}$ channels by diazoxide required the $\mathrm{W}_{\mathrm{A}}$ motifs of NBF1 and not NBF2 [40].

The diverse isoforms of SUR, when co-expressed in various combinations with Kir subunits, demonstrates different sensitivities $[29,36]$. For example the SUR2A / Kir6.2 complex regulates the activity of cell $\mathrm{K}_{\mathrm{ATP}}$ in cardiac and skeletal muscle. This combination is more sensitive to pinacidil than to diazoxide [29]. The SUR2B / Kir6.2 complex regulates the cell $\mathrm{K}_{\mathrm{ATP}}$ activity of smooth muscle and is sensitive to both pinacidil and diazoxide [30]. Thus, the sensitivity of cell $\mathrm{K}_{\mathrm{ATP}}$ to sulfonylureas, diazoxide and cromakalim requires the presence of SUR and the activation of the cellK $_{\text {ATP }}$ by Mg-ADP also requires the presence of SUR [36]. 
The verity that SUR1 contains two NBF whereas Kir6.2 has none, favors the assumption that inhibition of the channel by ATP requires binding of ATP to SUR $[29,31]$. The sensitivity of truncated Kir6.2 to ATP is enhanced by SUR1 as is evident from the shifting of $\mathrm{K}_{\mathrm{i}}$ from approximately $100 \mu \mathrm{M}$ to $10 \mu \mathrm{M}$ [36].

As per recent studies it has been demonstrated that the Kir and the SUR subunits are associated with 1:1 stoichiometry $[41,42,43,77]$. The data also indicate that the channel pore of cellK $\mathrm{K}_{\mathrm{ATP}}$ is lined by four Kir subunits and four SUR regulatory subunits surrounding it, eventually functioning as a hetero-octameric structure $[72$, 77].

The mitoK $\mathrm{K}_{\mathrm{ATP}}$ is thought to be qualitatively similar to the cellK $\mathrm{ATP}_{\mathrm{AT}}$, comprising the potassium conducting pore forming Kir subunit and the regulatory SUR subunit surrounding it. [51, 65, 90] [Fig 2]

\subsection{Mitochondrial $\mathbf{K}_{\mathrm{ATP}}$ Channels $\left(\right.$ MitoK $\left._{\mathrm{ATP}}\right)$}

Inoue et al., in 1991, through their patch clamp studies on fused giant mitoplasts (mitochondria stripped of their outer membrane) from rat liver mitochondria, first reported the existence of ATP sensitive $\mathrm{K}^{+}$channels in the inner membrane of the mitochondria [44]. The principal properties of mito $\mathrm{K}_{\mathrm{ATP}}$ include its improved sensitivity to $\mathrm{K}^{+}$ions in comparison to $\mathrm{Na}^{+}$and $\mathrm{TEA}^{+}$, high affinity inhibition with ATP and long chain acyl-CoA esters [44, 45], KCOs activation of the ATP inhibited 
channels [46, 47], and inhibition of the channel by glyburide, glibenclamide and 5hydroxydecanoate (5HD) $[45,47,48]$. All these physiological and pharmacological actions exhibited by mitoK $\mathrm{ATP}_{\mathrm{AT}}$ are thus similar to cellK $\mathrm{K}_{\mathrm{ATP}}$, although with a much lower conductance $\left(10 \mathrm{pS}\right.$ in $100 \mathrm{mmol} / \mathrm{L}$ cytosolic $\mathrm{K}+$ and $33 \mathrm{mmol} / \mathrm{L}$ matrix $\left.\mathrm{K}^{+}\right)$[44].

\subsection{Regulation of matrix volume by MitoK $_{\text {ATP }}$}

The opening of mitoK $\mathrm{K}_{\mathrm{ATP}}$ has been proposed to cause an increase in steady state matrix volume, respiratory stimulation (uncoupling), and alkalization of the mitochondrial matrix $[72,77]$. The electrophoretic $\mathrm{K}^{+}$uptake across the inner mitochondrial membrane is mediated through the process of diffusion and mitoK $\mathrm{ATP}_{\mathrm{AT}}$, as demonstrated by the mitochondrial potassium cycle [Fig. 1]. This influx of $\mathrm{K}^{+}$under steady state is balanced by the electrophoretic $\mathrm{H}^{+}$efflux through the electron transport chain. The mitochondrial matrix volume is determined by the net flux of $\mathrm{K}^{+}$across the inner membrane along with the flux of anions like phosphate and osmotically regulated water $[49,70,72,77]$. Opening of the mitoK $\mathrm{ATP}_{\mathrm{ATP}}$ leads to the influx of $\mathrm{K}^{+}$ across the inner mitochondrial membrane and an eventual swelling of the mitochondrial matrix, with a minimal effect on the matrix $\mathrm{K}^{+}$concentration. This net influx of $\mathrm{K}^{+}$activates the electroneutral $\mathrm{K}^{+} / \mathrm{H}^{+}$antiporter that provide a compensatory $\mathrm{K}^{+}$efflux so as to maintain a new steady state for a higher matrix volume [49-51]. The proton motive force derived from the electron transport chain provides the required energy to cause the movement of ions across the membrane. [Fig 1] 


\subsection{Oxidative phosphorylation}

The electrons carried by NADH and $\mathrm{FADH}_{2}$ get combined with molecular oxygen through the electron transport chain. Peter Mitchell proposed the chemiosmotic hypothesis in order to understand the synthesis of ATP through the coupling of substrate oxidation [52]. The energy required to pump the $\mathrm{H}^{+}$across the inner mitochondrial membrane from the matrix to the intermembrane space, is derived from the movement of electrons from the hydrogens on $\mathrm{NADH}$ and $\mathrm{FADH}_{2}$, as they pass along the respiratory chain. The synthesis of ATP by ATP synthase is mediated through the electrochemical gradient created by the movement of electrons. Oxidative phosphorylation is eventually concluded by the catalytic translation of ADP and Pi to ATP [52].

\subsection{Myocardial Ischemia and cardioprotection}

Myocardial ischemia is a phenomenon of reduced blood supply to heart muscle due to the constriction or obstruction of the coronary arteries, resulting in an imbalance between the supply and demand for coronary arterial blood supply. As a result of this imbalance there is an accumulation of potentially toxic metabolites such as protons, carbon dioxide and lactic acid. Also there is a dearth of oxygen, substrates and energy in the tissues. The energy for myocardial contractility is derived from mitochondrial oxidative phosphorylation which subsequently influences the myosin ATPase activity. 
The functions of the mitochondria are thus of prime importance in the molecular events that lead to compromised myocardial function. [75]

Subjecting the myocardium to repetitive alternating periods of ischemia followed by reperfusion, eventually followed by a prolonged ischemia-reperfusion, reflects ischemic-preconditioning (IPC) [75, 82]. Following ischemia, there is ATP depletion and subsequent reperfusion washes out the ischemic metabolites [53]. KCOs when used during ischemic preconditioning are cardioprotective, as evidenced by the size of the heart muscle infarct $[20,54,75,82]$. This protective effect of KCOs is blocked by glyburide, glibenclamide and 5-hydroxydecanoate (5HD) [19, 20, 55, 75, 82].

$\mathrm{KCOs}$ through their action on the cardiac cell $\mathrm{K}_{\mathrm{ATP}}$ are considered to cause a shortening of the action potential duration (APD) and hence protect the ischemic myocardium [56]. However, a lack of correlation between monophasic APD and cardioprotection by KCOs has resulted in contradicting this hypothesis, thus suggesting that the site of action of KCOs in cardiac muscle cells is discrete from cellK $\mathrm{K}_{\mathrm{ATP}}[57,58]$. This discrete site of action of cardioprotective effects of various KCOs is believed to be the mitoK ${ }_{\text {ATP. }}[65,72]$

\subsection{MitoK $\mathrm{K}_{\mathrm{ATP}}$ as a receptor for $\mathrm{KCOS}$ and their inhibitors}

MitoK $_{\mathrm{ATP}}$, a central intracellular pharmacological receptor is inhibited by ATP, and this inhibited mitoK ${ }_{\text {ATP }}$ is potentially activated by $\operatorname{KCOs}[46,47,48,59,60]$. Cromakalim and Diazoxide, the prime activators of mitoK $_{\mathrm{ATP}}$, act in the low 
micromolar range [46]. The distinct nature of the two cardiac $\mathrm{K}_{\mathrm{ATP}}$ channels i.e., cell $\mathrm{K}_{\mathrm{ATP}}$ and mitoK $\mathrm{K}_{\mathrm{ATP}}$ could probably be established through diazoxide which is more potent in activating the cardiac mitoK $\mathrm{ATP}(\mathrm{K} 1 / 2,0.4 \mu \mathrm{mol} / \mathrm{L})$, roughly 2000 times more potent than for activating cardiac cell $\mathrm{K}_{\mathrm{ATP}}(855 \mu \mathrm{mol} / \mathrm{L})$ [46]. Glyburide, glibenclamide and 5HD, when studied in intact mitochondria, have been shown to act as inhibitors of mitoK $\mathrm{ATP}_{\mathrm{A}}$ in the presence of ATP, $\mathrm{Mg}^{+2}$ and a pharmacological opener such as diazoxide, cromakalim, or a physiological opener such as GTP [48].

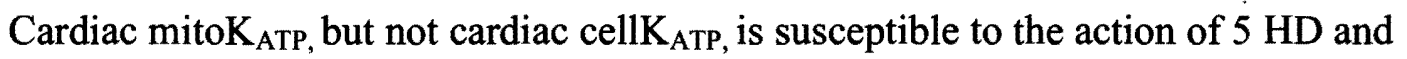
diazoxide and the cardioprotective effects of diazoxide are blocked by 5 HD [47]. It was eventually hypothesized by Garlid et al. that the phenomena of cardioprotection by KCOs in cardiac muscle cells was mediated through mitoK ATP $_{\text {[47]. Liu et al. }}$ through their experiments on intact ventricular myocytes, showed that diazoxide was mitoK $_{\mathrm{ATP}}$ specific and not cellK $\mathrm{K}_{\mathrm{ATP}}$ specific [59]. Protein kinase C (PKC) mediated activation of mitoK $\mathrm{K}_{\mathrm{ATP}}$ is a key element in the phenomenon of ischemicpreconditioning (IPC), as emphasized by Sato et al. [60-64].

It was recommended by Inoue et al. [44] and Halestrap [83] that the regulatory sites of the mitoK $\mathrm{ATP}_{\mathrm{AT}}$ nucleotides faced the mitochondrial matrix. Subsequently Garlid et al. through their studies on mitoK $_{\text {ATP }}$ reconstituted into proteoliposomes and lipid bilayer membranes (BLM), concluded that the mitoK $\mathrm{ATP}_{\mathrm{A}}$ was unidirectional with respect to 
nucleotide access and that the nucleotide binding sites of mito $\mathrm{K}_{\mathrm{ATP}}$ faced the cytosol [70].

\subsection{Sulfonylurea receptor of mitoK $_{\mathrm{ATP}}$ :}

Garlid et al. viewed that the mito $\mathrm{K}_{\mathrm{ATP}}$ comprised an inward-rectifying $\mathrm{K}^{+}$channel (mitoKir) and a regulatory sulfonylurea receptor (mitoSUR), as was thought of in cellK $_{\text {ATP }}[51,65,90]$. Paucek et al. through their studies using BODIPY-FL glyburide to photolabel inner mitochondrial membrane vesicles identified a protein that was precise and migrated at $63 \mathrm{kD}$ on SDS-Polyacrylamide gel electrophoresis $[66,67]$. The fraction containing the $63 \mathrm{kD}$ protein (identified on partial purification on DEAEcellulose medium), when reconstituted in lipid vesicles, exhibited mito $\mathrm{K}_{\mathrm{ATP}}$ properties. It was henceforth hypothesized to be the regulatory sulfonylurea receptor of mito $\mathrm{K}_{\mathrm{ATP}}$ [67].

Szewczyk et al. through photoaffinity labeling of sub-mitochondrial particles with $\left[\mathrm{I}^{125}\right]$-glibenclamide, recognized a $28 \mathrm{kD}$ inner mitochondrial membrane protein. This identified membrane protein demonstrated the activity of low-affinity sulfonylureabinding protein with an apparent $\mathrm{K}_{\mathrm{D}}$ of $360 \mathrm{nM}$ and $\mathrm{B}_{\mathrm{MAX}}$ of 48 pmol per mg of inner membrane protein [68]. 


\subsection{Kir subunit of mitoK $K_{\text {ATP. }}$}

Mironova et al., on reconstituting an ATP-dependent $\mathrm{K}^{+}$channel in the lipid bilayer using rat liver mitochondria, identified an activity with $55 \mathrm{kD}$ protein, that was inhibited with low affinity by ATP (K1/2 approximately $550 \mu \mathrm{M})$. They eventually suggested it to be the Kir subunit $[69,90]$. MitoK $\mathrm{ATP}_{\mathrm{A}}$ activity was witnessed in liposomes that were reconstituted with partially purified fraction using rat liver and beef heart mitochondria by Paucek et al. [45]. The identified protein contained a major protein band at $54 \mathrm{kD}[45]$, with a saturating conductance of $30 \mathrm{pS}(1 \mathrm{~mol} / \mathrm{L} \mathrm{KCl})$. Further studies are awaited that can help identify and sequence the alleged Kir subunit of mitoK $_{\text {ATP. }}$

The mitoK $\mathrm{ATP}_{\mathrm{AT}}$ activity characterized in the control mouse model would eventually facilitate in understanding further the subunit assembly of mitoK $\mathrm{K}_{\mathrm{ATP}}$ through the medium of genetically modified/transgenic mice and various immunological techniques. 


\section{CHAPTER 3}

\section{MATERIALS AND METHODS}

\subsection{Mitochondrial isolation:}

Inbred strain mice of type C57BL/6J from the Jackson lab were used for all the experiments. Three mice were used for each experiment in order to isolate significant amount of mitochondrial protein. The mice were anesthetized with $\mathrm{CO}_{2}$ for one minute, incised through the abdomen, sternotomy performed and the hearts were excised. It was our observation that the time interval between the hearts excision and completion of homogenization influenced the channel activity (brief period of 2 minutes); the lesser the time interval, the better the channel activity. The hearts were washed in ice cold Buffer A (250mM sucrose, 10mM HEPES, 5mM EGTA and pH 7.2). The hearts were pounded with protease $1 \mathrm{mg} / \mathrm{ml}$ (type XXIV Sigma). The suspension was diluted up to two to threefold with buffer A supplemented with $0.5 \%$ bovine serum albumin (BSA). The suspension was then poured into a motorized Teflon pestle so as to get it homogenized. The homogenized suspension was then centrifuged in a Sorvall centrifuge for 3 minutes at $1500 \mathrm{~g}$. The supernatant obtained was then centrifuged at $9000 \mathrm{~g}$ for 5 minutes. The consequential pellet was resuspended in Buffer A without BSA and centrifuged for 3 minutes at $2300 \mathrm{~g}$. The ensuing supernatant was centrifuged for 5 minutes at $9000 \mathrm{~g}$. The resulting final pellet was resuspended in Buffer A without BSA so as to have the final concentration as 35- 
$40 \mathrm{mg} / \mathrm{ml}$ protein and was placed on ice. This technique of mitochondrial isolation is in agreement with that described by Jaburek et al. [48, 72, 77, 84] (Appendix A). The mitochondrial protein concentration was projected by means of the Biuret reaction [71]. Mitochondrial protein was assayed within two hours of isolation. The isolated mitochondria were placed on ice and were continuously stirred with the help of a magnetic stirrer to ensure free oxygen access during the experiments. This practice is in agreement with the American Physiological Society's "Guiding principles in the Care and Use of Animals", and was permitted by the Institutional Animal Care and Use Committee (IACUC) at Portland State University, Oregon. [72, 77, 84]

\subsection{Assay Medium:}

The mitochondria were suspended in an assay medium consisting of potassium chloride $(\mathrm{KCl})(120 \mathrm{mM})$; EGTA $(0.1 \mathrm{mM})$ (chelator of calcium ions); succinate $(10 \mathrm{mM})$ (provides electrons to electron transport system); phosphoric acid (5mM); 0.5 $\mathrm{mM} \mathrm{MgCl} 2$ and $\mathrm{pH}$ 7.2. The osmolality range of the assay medium, as measured by the osmometer, was between $275-280$ mosmol $/ \mathrm{kg} \mathrm{H}_{2} \mathrm{O}$. All the runs were supplemented with $5 \mu \mathrm{M}$ Rotenone and $0.67 \mu \mathrm{M}$ Oligomycin. The experiments were performed at $30.5^{\circ} \mathrm{C}[72,77,84]$.

Rotenone is functional in inhibiting the reverse electron transfer from complex II to complex I of the electron transport chain. Oligomycin inhibits $\mathrm{F}_{0} \mathrm{~F}_{1}-\mathrm{ATP}$ synthase of 
the electron transport chain. The synthesis of ATP is henceforth interrupted and the membrane potential is subsequently decreased. $[72,77,84]$

The volume of the assay medium used for experiments involving rat heart mitochondria was $3 \mathrm{ml}$ in my lab. I tried to reduce the volume and work with the 1.5 $\mathrm{ml}$ assay medium in order to perform significant number of light scattering runs to validate the mitoK $_{\mathrm{ATP}}$ activity.

\subsection{Measurement of mitochondrial volume:}

$\mathrm{K}^{+}$uptake is assayed following the mitochondrial matrix swelling. The light scattering technique is functional in measuring the changes in mitochondrial volume that escort the net salt transport into the mitochondria. The light scattering technique is based on the principle that the reciprocal absorbance $\left(\mathrm{A}^{-1}\right)$ at $520 \mathrm{~nm}$ and $0.1 \mathrm{mg} / \mathrm{ml}$ of the mitochondrial suspension at $30.5{ }^{\circ} \mathrm{C}$, is linearly related to matrix volume, as described by Beavis et al. $[71,72] . \beta$ is a dimensionless factor that normalizes $A^{-1}$ (inverse absorbance) for mitochondrial protein concentration, $\mathrm{P}(\mathrm{mg} / \mathrm{ml})$

$$
\beta=P\left(A^{-1}-\alpha\right) / P_{s}
$$

$\alpha$ is a machine constant $(0.25$ for our apparatus $)$ and $P_{s}$ equals $1 \mathrm{mg} / \mathrm{ml} .[72,77,84]$

An increase in matrix volume, owing to the osmotic swelling of mitochondria (due to uptake of salts and water), is accompanied by a decrease in light intensity. The light scattering technique measures this change in matrix volume of the mitochondria. The 
light scattering technique is primarily functional in investigating the mitoK $\mathrm{ATP}_{\text {activity }}$ in intact isolated mitochondria. The light scattering technique is beneficial in comparison to the reconstitution studies, considering that the mitochondrial ion channels and the bioenergetic apparatus are intact and also the various regulatory agents could possibly be applied directly to the mitochondria. Limitations include the unphysiological ion gradient's usage, substrate or nucleotide concentrations, and a possible influence of neighboring organelle membranes [48]. The data measured by a Brinkmann PC 700 light probe is converted to digital information $\left(A^{-1}\right)$ using a "Lab view" program designed exclusively for use in our laboratory. [72, 84]

Diazoxide, and other hydrophobic compounds soluble in dimethyl sulfoxide (DMSO), are always added 2-3 seconds after the mitochondrial suspension to guarantee equal distribution. Also, diazoxide is not effective in the absence of ATP, since it cannot activate a channel that is previously in its open state. Similarly, 5 hydroxydecanoate ( 5

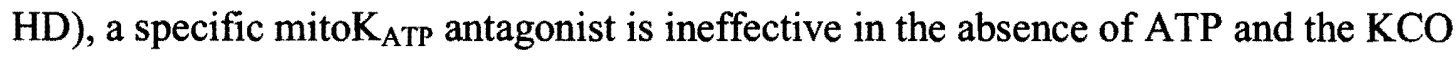
diazoxide. This is because $5 \mathrm{HD}$ prevents the diazoxide mediated mitoK $_{\mathrm{ATP}}$ activation, but by itself does not inhibit the channel activity. The same observations hold good for cromakalim, PMA and glibenclamide as well. Light scattering traces were initiated on adding the mitochondrial suspension with the first 5-7 seconds omitted for precision. The channel activity was followed over a period of 180 seconds. [72, 77, 84] 
The final concentration of the stock mitochondria added to the assay medium was 0.1 $\mathrm{mg}$ protein $/ \mathrm{ml}$. The volume of the assay medium was $1.5 \mathrm{ml}$ for each run. Data analysis followed each individual experiment. Rate of swelling was determined by the slope of the traces on addition of the various $\mathrm{KCOs,} \mathrm{activators} \mathrm{of} \mathrm{mitoK} \mathrm{ATP}_{\mathrm{ATP}}$ and their blockers. The analysis program used was "ORIGIN", a data-analysis program by Microcal (Northampton, MA, USA). [72, 84]

Statistical analysis: Data are presented as mean $+/$ SD. Data were analyzed using unpaired Student's t-test of the means using Microcal Origin software (Northampton, MA). A value of $P<0.05$ is considered statistically significant.

\subsection{Chemicals}

All the chemicals used for the experiments were from Sigma Chemical Co. (St. Louis, MO, USA). Mice were ordered from the Jackson laboratory (Maine, USA). 


\section{CHAPTER 4}

\section{KATP CHANNEL OPENERS AND BLOCKERS:}

One of the most credible means to establish and identify the functions of cardiac sarcolemmal and mitochondrial $\mathrm{K}_{\mathrm{ATP}}$ channels is through the medium of $\mathrm{K}_{\mathrm{ATP}}$ channel openers and blockers. The pharmacological agents could probably be classified as selective and non-selective based on their putative sites of action in heart, the former acting exclusively on the mitoK $\mathrm{ATP}_{\mathrm{AT}}$ and the latter acting either on $\operatorname{sarcK}_{\mathrm{ATP}} / \mathrm{mitoK}_{\mathrm{ATP}}$ as shown in Table 1 and represented structurally in figures 15 and 16.

\subsection{Non-selective $K_{\mathrm{ATP}}$ agonists:}

Cromakalim, synthesized in 1980 represents the archetype of the benzopyrans class of drugs. Used as a cardioprotective drug in experimental routines, it lacks specificity in its site of action (mitoK $\mathrm{K}_{\mathrm{ATP}}$ vs cell $\mathrm{K}_{\mathrm{ATP}}$ ). It functions in shortening the action potential duration (APD) and causes vasodilatation [80, 82].

Nicorandil, belongs to the pyridyl nitrate class of drugs and causes significant vasodilatation due to its NO (nitric oxide) donor properties. It has a non-specific site of action in the cardiac myocyte $[80,82]$.

P 1075 is a widely studied potent cyanoguanidine. It lacks selectivity versus the mitoK $_{\text {ATP }}$ as was shown in ischemia-reperfusion studies on rat and rabbit cardiac myocytes [82]. 


\subsection{Selective mitoK $\mathrm{K}_{\mathrm{ATP}}$ agonists:}

Diazoxide, a benzothiazidine class of drug is a selective mitoK $\mathrm{K}_{\mathrm{ATP}}$ agonist under normal conditions. It also causes activation of smooth muscle $\mathrm{K}_{\mathrm{ATP}}$ and endothelial $\mathrm{K}_{\mathrm{ATP}}$ isoforms. Diazoxide is probably the only $\mathrm{K}_{\mathrm{ATP}}$ opener that binds equivocally to SUR 1 and SUR 2B subunits. It is routinely used in low doses to establish the importance of mitoK $\mathrm{K}_{\mathrm{ATP}}$ in preconditioning. A long term use of diazoxide is related to the development of hyperglycemic state owing to its role in insulin inhibition [46, 82].

BMS-191095 ((3R)-trans-4-((4-chlorophenyl)- $N$-(1H-imidazol-2-ylmethyl)dimethyl$2 H$-1-benzopyran-6-carbonitril monohydrochloride) belongs to the benzopyrans class of drugs with a higher cardiac selectivity and anti-ischemic potency. It was shown to improve the post- ischemic cardiac function and a reduction in the LDH (lactate dehydrogenase) release. Grover et al. through their studies using reconstituted mitoK $_{\text {ATP }}$ observed that BMS191095 activated the mitoK $_{\text {ATP }}$ and the activation was inhibited by both $5 \mathrm{HD}$ and glibenclamide $[79,82]$.

\subsection{K KTP channel blockers:}

$5 \mathrm{HD}$ ( 5 hydroxydecanoate), regarded as a specific inhibitor of mitoK $\mathrm{K}_{\mathrm{ATP}}$, is used in most studies to assess the activity of the mitoK $\mathrm{ATP}_{\mathrm{AT}}$ channel. It has been observed that

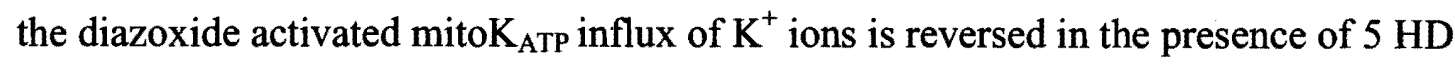
in isolated rat heart mitochondria [48]. 
Glibenclamide, an anti-diabetic drug belonging to the sulfonylurea class, is implemental in blocking the activity of the $\mathrm{K}_{\mathrm{ATP}}$ channel. It shows marked variability in its actions with different affinity grades, exhibiting SUR1 blocking properties involving pancreatic $\mathrm{K}_{\mathrm{ATP}}$ and the SUR2A/2B subunits expressed on the cardiac and the vascular cells $[80,82]$.

HMR 1098 belongs to the sulfonylthiourea class and is considered as a selective cell $_{\text {ATP }}$ blocker. It is generally used along with a non-specific $\mathrm{K}_{\mathrm{ATP}}$ blocker to examine the physiology of IPC [81]. 


\section{CHAPTER 5}

\section{RESULTS:}

The effects of ATP, KCOs (diazoxide, cromakalim), mitoK $\mathrm{ATP}_{\mathrm{A}}$ activators (such as PMA) and inhibitors (5 HD and glibenclamide) on mitochondrial matrix swelling are potassium-specific.

The mitochondrial potassium cycle is an important constituent in maintaining the mitochondrial volume homeostasis [Fig 1]. The swelling of the mitochondrial matrix is witnessed as an increase in light scattering and is proportional to the net salt influx $[72,77,84]$. The light scattering technique is functional in investigating the mitoK $\mathrm{K}_{\text {ATP }}$ activity in intact isolated mitochondria. The typical light scattering traces from control mouse heart mitochondria in a respiring $\mathrm{K}^{+}$rich medium are shown in figures $4-9$.

Figure 4 demonstrates light scattering traces from mouse heart mitochondria respiring in succinate supplemented $\mathrm{K}^{+}$medium at $30.5^{\circ} \mathrm{C}$. The light scattering parameter $\beta$, an index of matrix volume, is plotted against time. In the absence of ATP (open/control), the mitochondrial matrix attained a higher steady state volume. On addition of $200 \mu \mathrm{M}$ ATP there is an apparent lower rate of swelling and ultimately a lower steady state volume (ATP). The ATP inhibition of the channel was reversed by $30 \mu \mathrm{M}$ diazoxide (ATP + DZX), and the opening effect of diazoxide was blocked by $300 \mu \mathrm{M} 5 \mathrm{HD}$ $(\mathrm{ATP}+\mathrm{DZX}+5 \mathrm{HD}) \cdot[$ Fig. 4$]$ 
Figure 5 demonstrates light scattering traces from mouse heart mitochondria respiring in the same succinate supplemented $\mathrm{K}^{+}$medium at $30.5^{\circ} \mathrm{C}$. In the absence of ATP, the mitochondrial matrix scaled to a higher steady state volume. Addition of $200 \mu \mathrm{M}$ ATP lowered the rate of swelling. The inhibition of the channel by ATP was reversed by 30 $\mu \mathrm{M}$ diazoxide, and the activator effect of diazoxide was inhibited by $10 \mu \mathrm{M}$ glibenclamide. [Fig. 5]

Figures 6 and 7 demonstrate light scattering traces initiated from mouse heart mitochondria respiring in the same $\mathrm{K}^{+}$medium supplemented with succinate. It was evident that the mitochondria had swollen to a new steady state volume in the absence of ATP (open) and the addition of $200 \mu \mathrm{M}$ ATP lowered the swelling. The channel was re-activated by cromakalim $(50 \mu \mathrm{M})$ and this activator effect was inhibited by both $5 \mathrm{HD}(300 \mu \mathrm{M})$ and glibenclamide $(10 \mu \mathrm{M})$. [Fig. 6 \& 7]

Figures 8 and 9 illustrate the light scattering traces demonstrated by isolated mouse heart mitochondria respiring on succinate supplemented $\mathrm{K}^{+}$medium. The mitochondria, owing to the matrix swelling, attained a new steady state volume in the absence of ATP (open/control trace), an effect inhibited in the presence of $200 \mu \mathrm{M}$ ATP. On addition of a PKC $\varepsilon$ activator PMA $(0.2 \mu \mathrm{M})$, the mitoK ATP $_{\text {got reactivated }}$ and almost superimposed on the open trace. But this activated mitoK $\mathrm{K}_{\text {ATP }}$ was inhibited by both $5 \mathrm{HD}(300 \mu \mathrm{M})$ and glibenclamide $(10 \mu \mathrm{M})$. [Fig. $8 \&$ 9] 
Figures 10,11 and 12 graphically illustrate the summary of the percentage mitoK $\mathrm{ATP}_{\mathrm{P}}$ activity exhibited by isolated mouse heart mitochondria in the presence of activators diazoxide, cromakalim, PMA, and inhibitors $5 \mathrm{HD}$, glibenclamide. The data establish the capacity of ATP to inhibit the channel, the openable effects of various KCOs and the inhibitory actions of $\mathrm{K}^{+}$channel blockers. $P$ value was less than 0.05 and hence statistically significant. The data also validates the monitoring capacity of the assay medium. The results summarized represent five independent experiments for each combination. Data are presented as mean $+/$ SD. Data were analyzed using unpaired Student's t-test of the means using Microcal Origin software. $\mathrm{P}<0.05$ is considered statistically significant.

Figure 13 represents typical light scattering traces from rat heart mitochondria respiring in succinate supplemented $\mathrm{K}^{+}$medium $(120 \mathrm{mM})$ at $30.5^{\circ} \mathrm{C}$. It can be noted that the mitochondrial matrix had swollen to a higher steady state in the absence of ATP (open/control). When $200 \mu \mathrm{M}$ ATP was added it resulted in a lower steady state volume. ATP inhibition was overcome by $30 \mu \mathrm{M}$ diazoxide and the diazoxide activated channel was inhibited by $300 \mu \mathrm{M} 5 \mathrm{HD}$ [Fig. 13]. The light scattering traces look similar to those in the mouse heart mitochondria. The results obtained with the combination of diazoxide and $5 \mathrm{HD}$ were reproducible by combining diazoxide + glibenclamide $(10 \mu \mathrm{M})$, cromakalim $(50 \mu \mathrm{M})+5 \mathrm{HD}$ or cromakalim + glibenclamide, and also PMA $(0.2 \mu \mathrm{M})+5 \mathrm{HD}$ or PMA + glibenclamide. (data not shown) 
Figure 14 demonstrates bar graphs representing the comparison between percentage mitoK $_{\mathrm{ATP}}$ activity exhibited by rat and mouse heart mitochondria under the same experimental conditions. Rates in the absence of ATP were set as $100 \%$ and in the presence of ATP as $0 \%$. The effects of various KCOs and blockers are assessed in relation to the set controls. It can be seen that the percentage mitoK $\mathrm{K}_{\mathrm{ATP}}$ activity exhibited by mouse heart mitochondria is comparable to that exhibited by rat heart mitochondria when subjected to various potassium channel openers and their blockers. Data are presented as mean $+/-$ SD. Data were analyzed using unpaired Student's t-test of the means using Microcal Origin software.

\subsection{Mechanism of activation of mitoK $K_{A T P}$ by PMA:}

PMA is a protein kinase $\mathrm{C}$ epsilon (PKCE) activator which eventually activates the mitoK $_{\text {ATP. The activation of } \mathrm{PKC} \varepsilon \text { phosphorylates the mitoK }}$ ATP and ultimately opens

it. PKC $\varepsilon$ has been shown to be bound to the inner membrane of the mitochondria and associated in a functional complex with mitoK $\mathrm{ATP}_{\mathrm{T}}$. This was demonstrated using the techniques of detergent extraction and chromatographic isolation of mitochondrial membrane proteins. The PKC $\varepsilon$ activated mitoK $_{\mathrm{ATP}}$ results in an influx of potassium, an effect negated in the presence of phosphatases. The $\mathrm{K}^{+}$influx causes the matrix alkalinization, retarding the reduction of $\mathrm{Q}$ to $\mathrm{QH}_{2}$ at Complex 1 of the electron transport chain and eventually resulting in the $\mathrm{H}_{2} \mathrm{O}_{2}$ production by reducing the

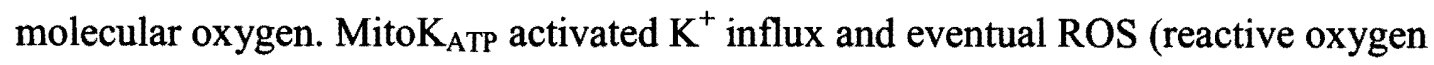


species) production is mediated through the $\mathrm{KCOs}$ and also mitoK $\mathrm{K}_{\mathrm{ATP}}$ associated

PKC $\varepsilon$ activation [75, 78]. [Fig 3]

When used in the $0.2 \mu \mathrm{M}$ concentration, the PKC $\varepsilon$ mediated activation of mito $\mathrm{K}_{\mathrm{ATP}}$ by

PMA was inhibited by both 5HD and glibenclamide. [Fig 8, 9, 12] 


\section{Table 1:}

Pharmacological agents currently under investigation to validate the $\mathbf{K}_{\mathrm{ATP}}$ channel activity:

\begin{tabular}{|c|c|c|}
\hline Pharmacological agent & $\begin{array}{l}\text { Putative site of action in } \\
\text { heart }\end{array}$ & Agonist/Antagonist \\
\hline Cromakalim & CellK $_{\text {ATP }} /$ MitoK $_{\text {ATP }}$ & Agonist \\
\hline Nicorandil & CellK $_{\text {ATP }} /$ MitoK $_{\text {ATP }}$ & Agonist \\
\hline Diazoxide & MitoK $_{\text {ATP }}$ & Agonist \\
\hline P-1075 & CellK $_{\text {ATP }} /$ MitoK $_{\text {ATP }}$ & Agonist \\
\hline BMS191095 & MitoK $_{\text {ATP }}$ & Agonist \\
\hline 5-hydroxydecanoate & MitoK $_{\text {ATP }}$ & Antagonist \\
\hline Glyburide/Glibenclamide & MitoK $_{\text {ATP }} /$ CellK $_{\text {ATP }}$ & Antagonist \\
\hline HMR-1098 & CellK $_{\text {ATP }}$ & Antagonist \\
\hline TPP & MitoK $_{\text {ATP }} /$ CellK $_{\text {ATP }}$ & Antagonist \\
\hline
\end{tabular}

Table 1 demonstrates the various pharmacological agents currently under investigation worldwide to assess the ATP-sensitive potassium channel $\left(\mathrm{K}_{\mathrm{ATP}}\right)$ activity along with their putative sites of action in heart and their mode of action (agonist vs. antagonist). Cromakalim, Nicorandil and P-1075 are considered as non-selective agonists of $K_{\text {ATP }}$ since they are believed to act on the cellK $\mathrm{K}_{\mathrm{ATP}}$ and the mitoK $_{\mathrm{ATP}}$. Diazoxide and BMS191095 are considered to be mitoK $_{\mathrm{ATP}}$ specific agonists. 5-hydroxydecanoate (5HD) is a mitoK ${ }_{A T P}$ specific antagonist and HMR-1098 is a cellK $\mathrm{K}_{\text {ATP }}$ specific antagonist. Glyburide, Glibenclamide and TPP are non-selective $\mathrm{K}_{\mathrm{ATP}}$ channel antagonists. 


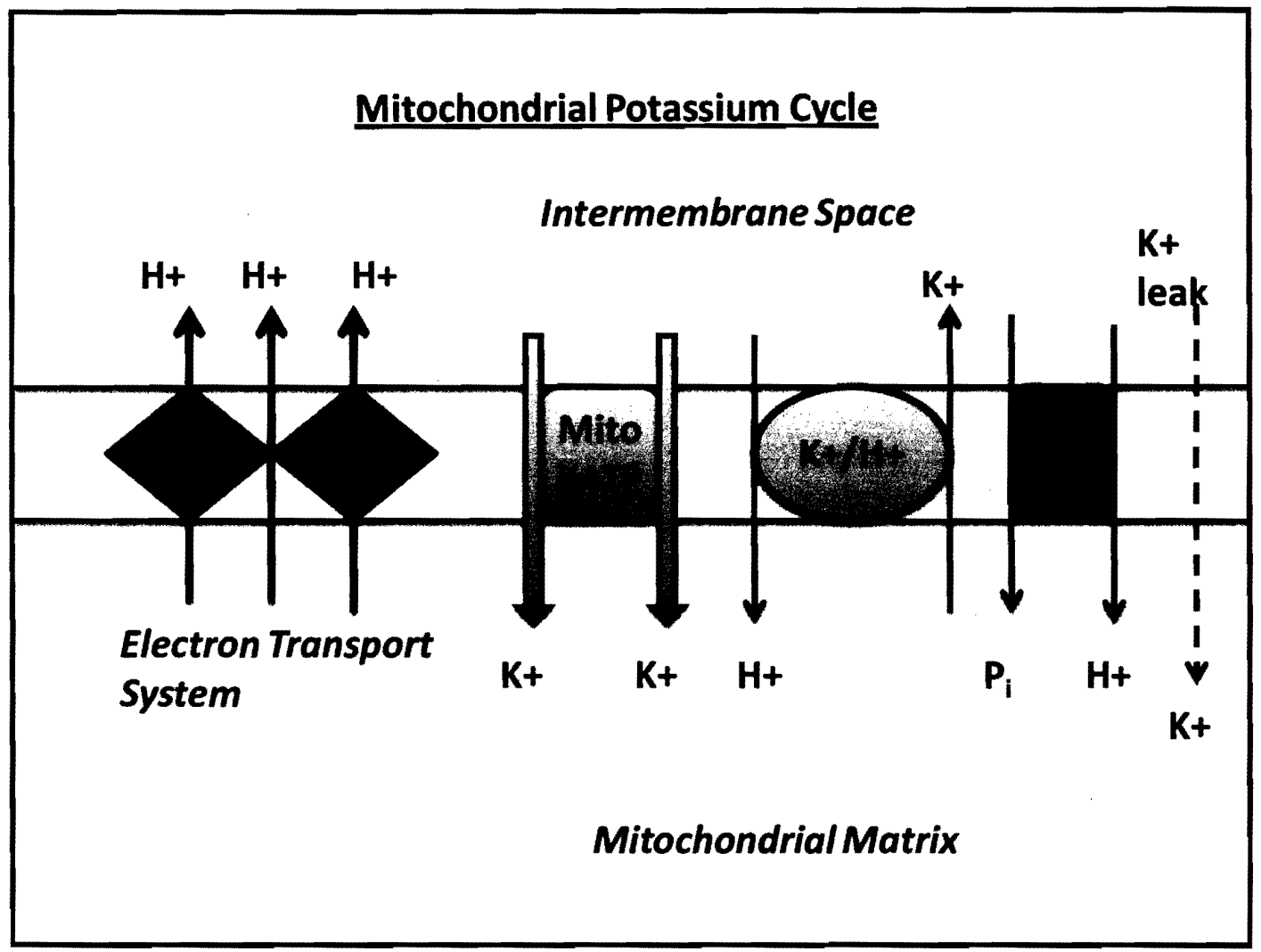

Fig 1: Mitochondrial Potassium cycle. The proton motive force that is generated by the electron transport system creates a membrane potential that drives $\mathrm{K}^{+}$influx via diffusion $\left(\mathrm{K}^{+}\right.$leak) and mitoK $\mathrm{KTP}_{\mathrm{ATP}}$ (located on the inner membrane). The electroneutral $\mathrm{Pi} / \mathrm{OH}$ exchanger drives phosphate inside so that the net $\mathrm{K}^{+}$influx is accompanied by anions and osmotically obligated water. The electroneutral $\mathrm{K}^{+} / \mathrm{H}^{+}$antiporter regulated on the matrix side by volume changes, $\mathrm{Mg}^{+2}$ and $\mathrm{H}^{+}$, provides an efflux of excess $\mathrm{K}^{+}$ accompanied by $\mathrm{Pi}$ and water, thereby preventing excessive matrix swelling. $[49,50$, $51,77]$ 


\section{Proposed interaction of regulatory ligands with mito $K_{\text {ATP }}$}

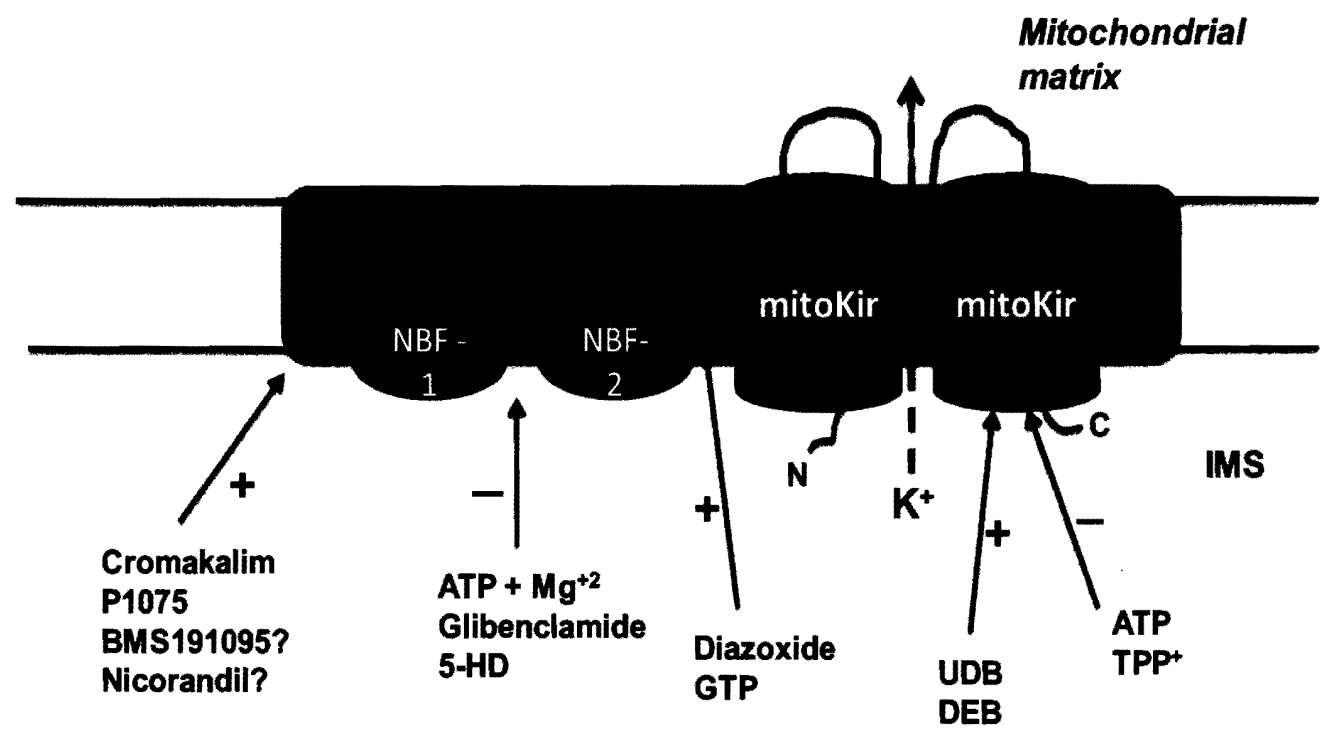

Fig 2: A proposed illustration of the mitoK $K_{\text {ATP }}$ channel subunits with the possible interaction sites of the regulatory ligands (illustration modified from reference [90]). MitoK $_{\mathrm{ATP}}$ is thought to be represented by four $55-\mathrm{kDa}$ Kir subunits and four 63 $\mathrm{kDa}$ SUR subunits, functioning as a hetero-octamer. MitoKir is viewed as a conduction pore of the channel and is surrounded by the regulatory SUR subunits that contain one or more nucleotide binding folds (NBF). The Kir subunits regulate the movement of $\mathrm{K}^{+}$across the membrane. The Kir subunits are thought to mediate the inhibitory effects of ATP (in the absence of $\mathrm{Mg}^{+2}$ ) and TPP ${ }^{+}$, and activation effects of UDP and DEB. The SUR subunits, belonging to the ABC family, demonstrate the sites of possible inhibition by ATP $+\mathrm{Mg}^{+2}$, Glibenclamide and 5-HD. The activation of the channel by diazoxide, GTP, cromakalim, P1075 and possibly BMS191095 and nicorandil, is thought to be mediated through the SUR subunits. [90] 
Intramitochondrial signalling pathway \& PMA mode of action

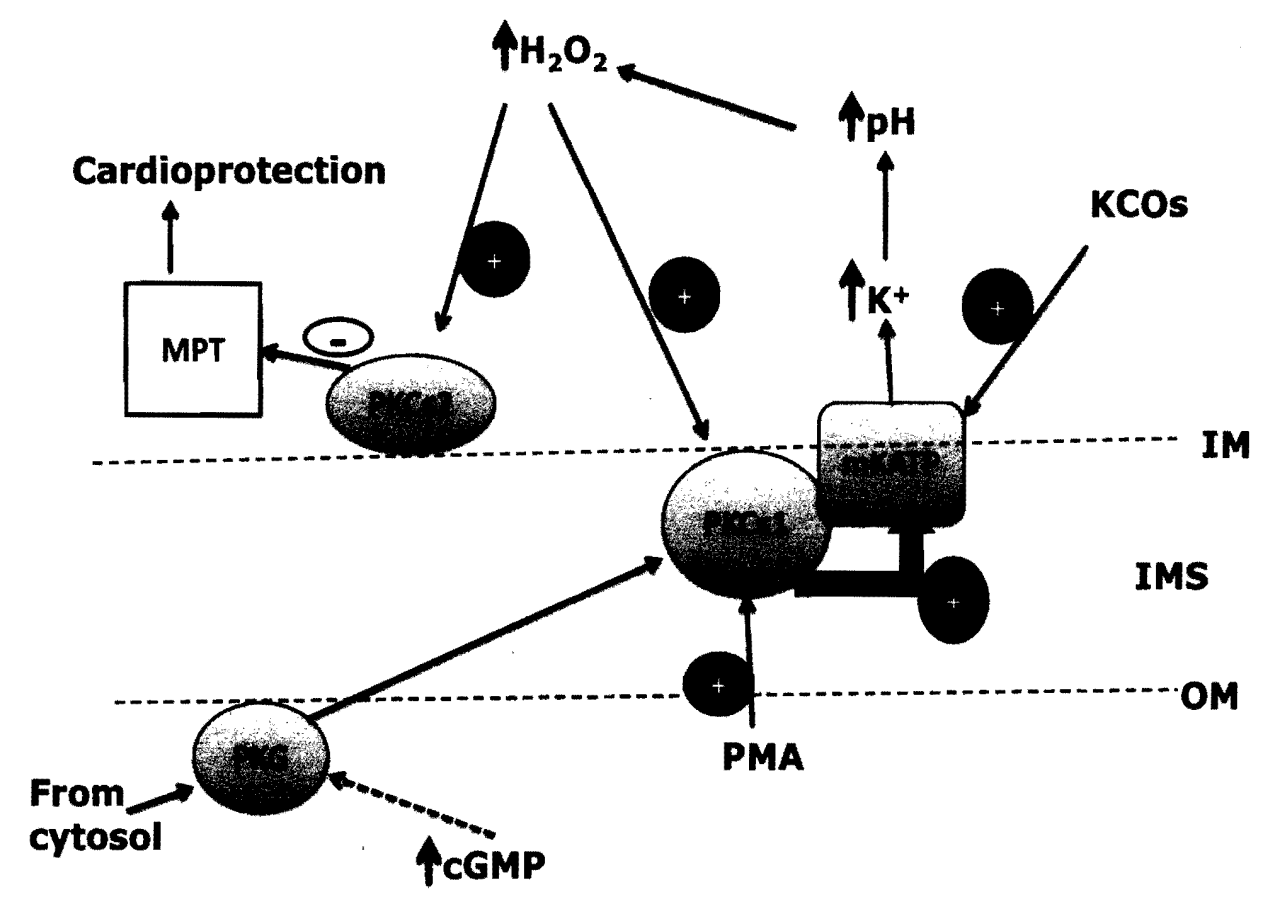

Fig 3: Intramitochondrial signalling pathway triggered by cGMP activated mitoK $_{\mathrm{ATP}}$ (illustration modified from reference [78]). PKG delivers the signals to

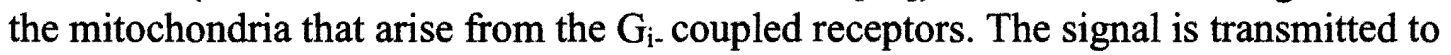
PKC $\varepsilon 1$ located on the inner mitochondrial membrane (IM) from PKG phosphorylation of an unknown mitochondrial outer membrane (OM) protein. Activated PKC 1 l causes phosphorylation and opening of the mitoK $\mathrm{ATP}_{\mathrm{ATP}}$ MitoK $_{\mathrm{ATP}}$ opening via PKC $\varepsilon 1$ activation by PMA or by $\mathrm{K}_{\mathrm{ATP}}$ channel openers such as diazoxide or cromakalim results in $\mathrm{K}^{+}$ influx, increase in matrix $\mathrm{pH}$ and increased $\mathrm{H}_{2} \mathrm{O}_{2}$ (reactive oxygen species) production. The $\mathrm{H}_{2} \mathrm{O}_{2}$ produced inturn activates $\mathrm{PKC} \varepsilon 1$ and $\mathrm{PKC} \varepsilon 2$. The activated PKCE2 inhibits the mitochondrial permeability transition (MPT) which eventually decreases cell necrosis, infarct size and inhibits apoptosis. [75, 78, 82]

Abbreviations used: cGMP, cyclic Guanosine monophosphate; PKG, protein kinase G; PMA, Phorbol 12-myristate-13-acetate; OM, outer membrane; IM, inner membrane; IMS, inter membranous space; $\mathrm{PKC} \varepsilon$, protein kinase $\mathrm{C}$ epsilon; $\mathrm{H}_{2} \mathrm{O}_{2}$, hydrogen peroxide; MPT, mitochondrial permeability transition; mkATP, mitochondrial $\mathrm{K}_{\mathrm{ATP}}$; "+" sign indicates activation; "“-" sign indicates inhibition 
Light scattering traces illustrating mitoK $\mathrm{KTP}_{\mathrm{Activity}}$ in mouse heart mitochondria:

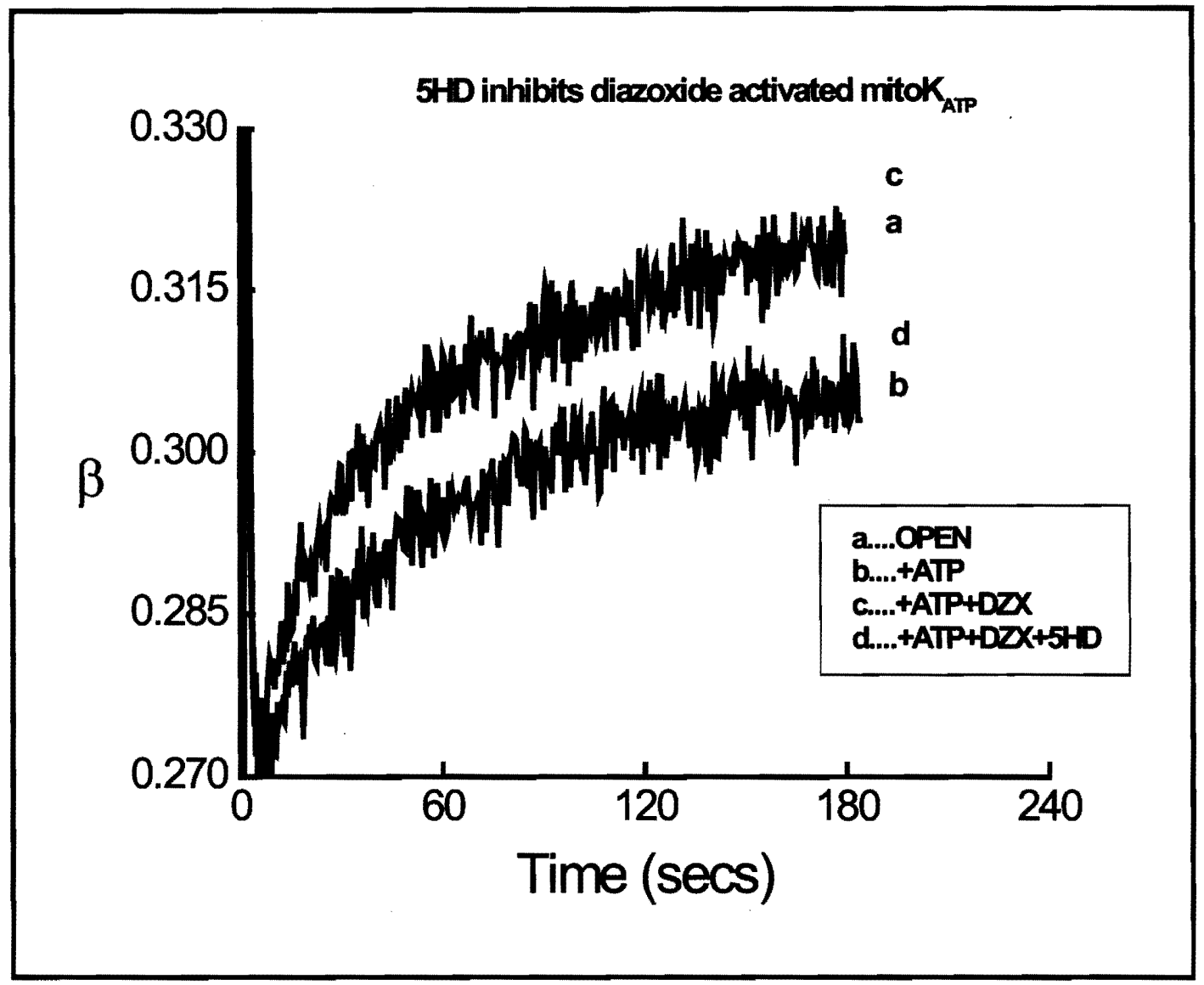

Fig 4: 5-hydroxydecanoate (5 HD) inhibits the pharmacological opening of mitoK $_{\mathrm{ATP}}$ by diazoxide. Light scattering traces from mouse heart mitochondria respiring on succinate in $\mathrm{K}^{+}$medium $(120 \mathrm{mM})$ at $30.5{ }^{\circ} \mathrm{C}$. The light scattering parameter $\beta$, an index of matrix volume, is plotted against time.

Trace a: $\mathrm{K}^{+}$influx in the absence of ATP (open/control)

Trace b: $\mathrm{K}^{+}$influx in the presence of $0.2 \mathrm{mM} \mathrm{ATP}$

Trace c: Reversal of ATP inhibition by $30 \mu \mathrm{M}$ Diazoxide (the trace almost superimposes on the open trace)

Trace d: Reinhibition by $300 \mu \mathrm{M}$ 5-hydroxydecanoate in the presence of $30 \mu \mathrm{M}$ diazoxide and $0.2 \mathrm{mM} \mathrm{ATP} \mathrm{(the} \mathrm{trace} \mathrm{almost} \mathrm{superimposes} \mathrm{on} \mathrm{trace} \mathrm{'} b$ ') 


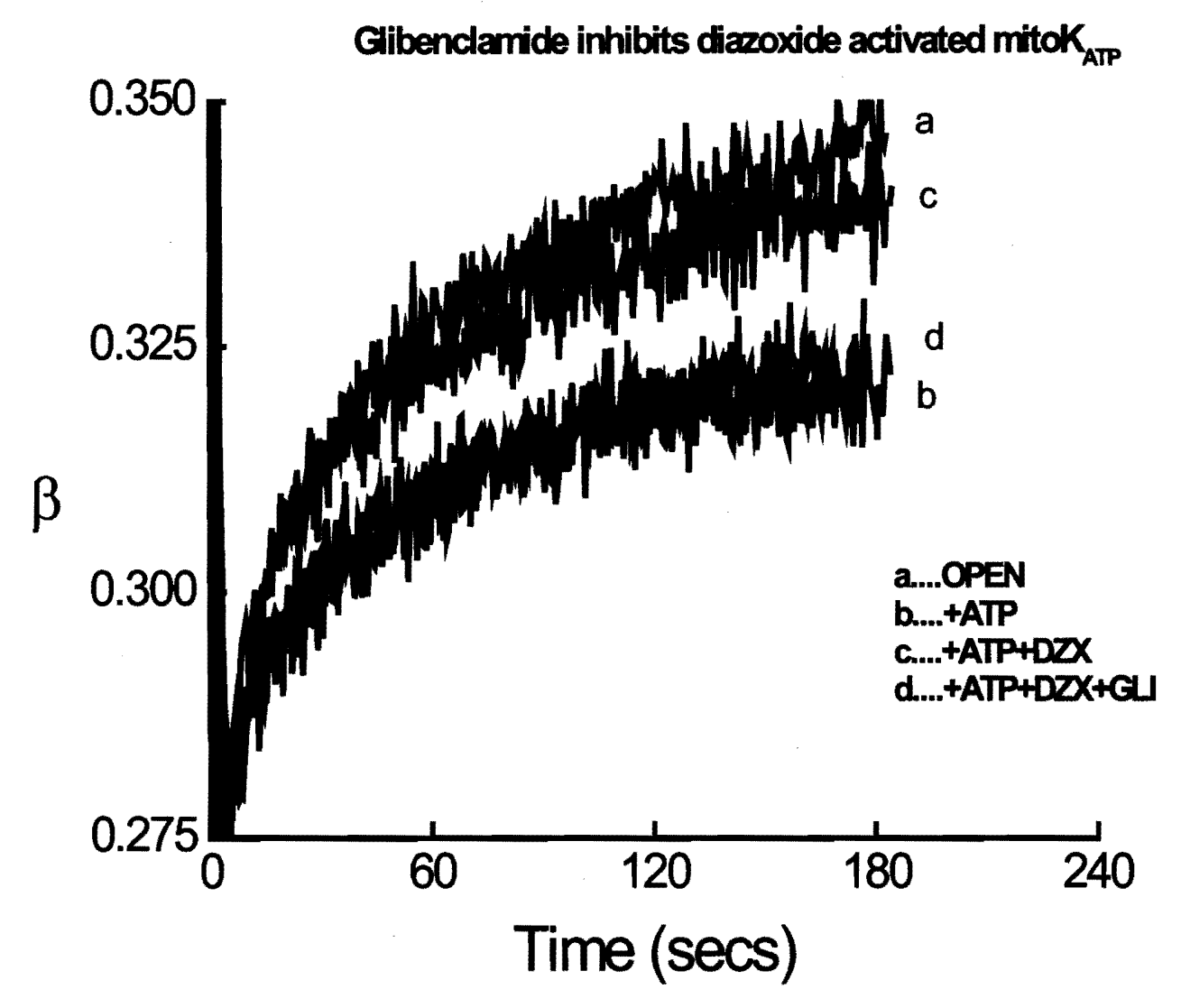

Fig 5: Glibenclamide inhibits the pharmacological opening of mitoK ${ }_{\mathrm{ATP}}$ by diazoxide. Light scattering traces of mouse heart mitochondria respiring on succinate rich $\mathrm{K}^{+}$medium $(120 \mathrm{mM})$ at $30.5^{\circ} \mathrm{C}$. The light scattering parameter $\beta$, an index of matrix volume, is plotted against time.

Trace a: Resting mitoK $\mathrm{ATP}_{\mathrm{A}}$ channel in open state (control)

Trace b: Inhibition of mitoK $\mathrm{ATP}_{\mathrm{ATP}}$ by $(0.2 \mathrm{mM})$

Trace c: Activation of mitoK $\mathrm{K}_{\mathrm{ATP}}$ by diazoxide $(30 \mu \mathrm{M})$ in the presence of ATP $(0.2$ $\mathrm{mM}$ ) (the trace almost superimposes on the open trace)

Trace d: Inhibition of diazoxide activated mitoK $\mathrm{ATP}_{\mathrm{AP}}$ by glibenclamide $(10 \mu \mathrm{M})$ in the presence of ATP (the trace almost superimposes on trace ' $b$ ') 


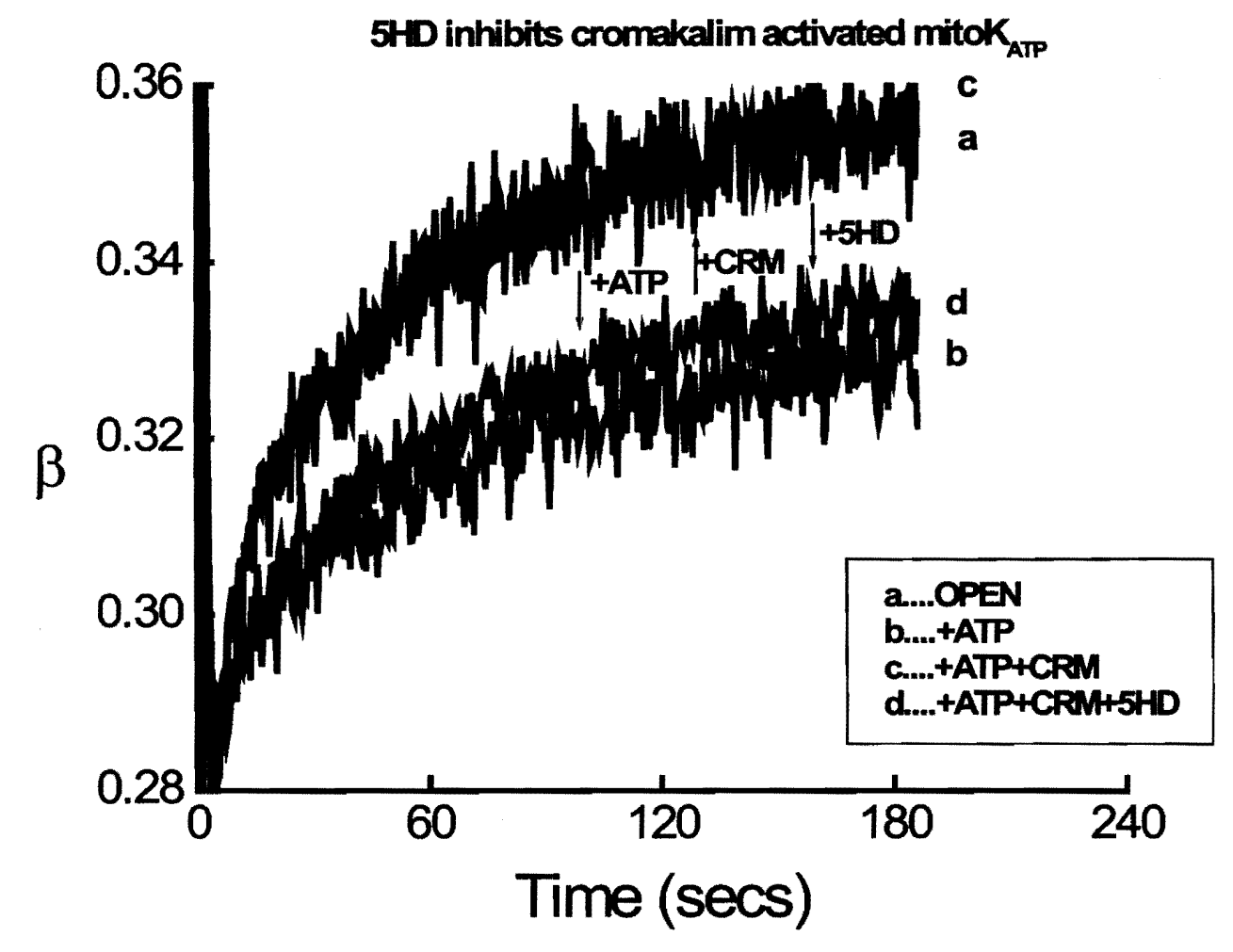

Fig 6: 5-hydroxydecanoate (5 HD) inhibits cromakalim (CRM) activated mitoK $_{\mathrm{ATP}}$. Light scattering traces showing the activity of mito $K_{\mathrm{ATP}}$ in mouse heart mitochondria respiring on succinate supplemented $K^{+}$medium $(120 \mathrm{mM})$ at 30.5 ${ }^{0} \mathrm{C}$. The light scattering parameter $\beta$, an index of matrix volume, is plotted against time.

Trace a: Resting mitoK $\mathrm{K}_{\mathrm{ATP}}$ channel in open state (control)

Trace b: Inhibition of mitoK $\mathrm{KTP}_{\mathrm{AT}}$ by ATP $(0.2 \mathrm{mM})$

Trace c: Activation of mitoK $\mathrm{K}_{\mathrm{ATP}}$ by cromakalim $(50 \mu \mathrm{M})$ in the presence of ATP $(0.2$ $\mathrm{mM}$ ) (the trace almost superimposes on control trace)

Trace d: Inhibition of cromakalim activated mitoK $\mathrm{ATP}_{\mathrm{AT}}$ by $5 \mathrm{HD}(300 \mu \mathrm{M})$ in the presence of ATP (the trace almost superimposes on trace ' $b$ ') 


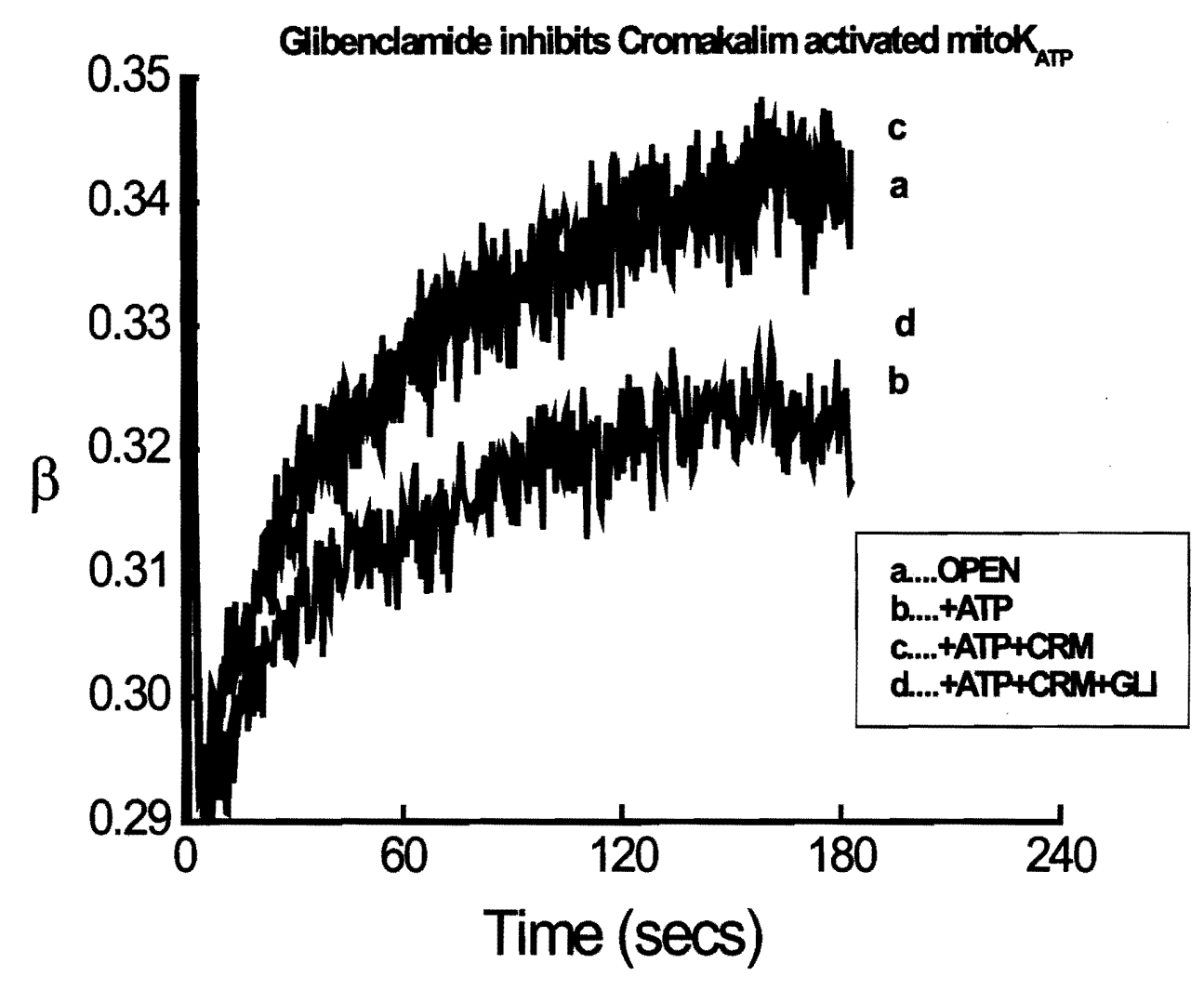

Fig 7: Glibenclamide inhibits the cromakalim activated mitoK $\mathrm{ATP}_{\mathrm{AT}}$ Light scattering traces showing the activity of mitoK $K_{A T P}$ in mouse heart mitochondria respiring on succinate supplemented $\mathrm{K}^{+}$medium $(120 \mathrm{mM})$ at $30.5^{\circ} \mathrm{C}$. The light scattering parameter $\beta$, an index of matrix volume, is plotted against time.

Trace a: Resting mito $\mathrm{K}_{\mathrm{ATP}}$ channel in open state (control)

Trace b: Inhibition of mitoK $\mathrm{ATP}_{\mathrm{ATP}}$ bTP $(0.2 \mathrm{mM})$

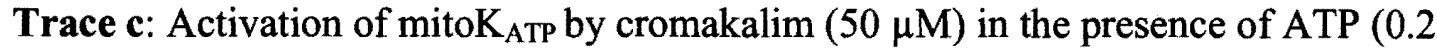
$\mathrm{mM}$ ) (trace almost superimposing on trace ' $a$ ')

Trace d: Inhibition of cromakalim activated mitoK $\mathrm{ATP}_{\mathrm{P}}$ by glibenclamide $(10 \mu \mathrm{M})$ in the presence of ATP (the trace almost superimposes on trace ' $b$ ') 


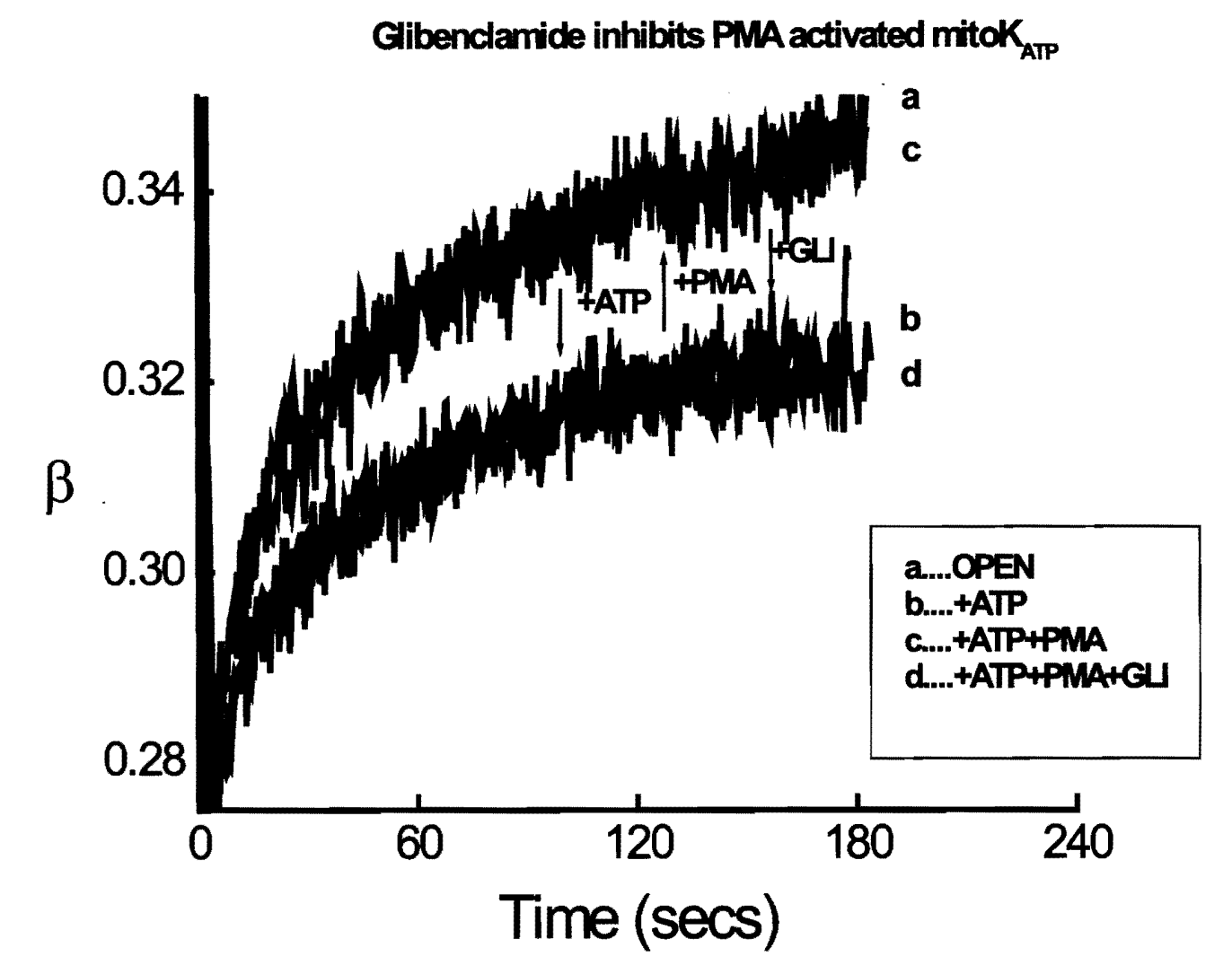

Fig 8: Glibenclamide inhibits the PMA activated mitoK $\mathrm{KTP}_{\mathrm{AT}}$ Light scattering traces showing the activity of mitoK $K_{A T P}$ in mouse heart mitochondria respiring on succinate supplemented $\mathrm{K}^{+}$medium $(120 \mathrm{mM})$ at $30.5^{\circ} \mathrm{C}$. The light scattering parameter $\beta$, an index of matrix volume, is plotted against time.

Trace a: Resting mitoK $\mathrm{ATP}_{\mathrm{AT}}$ channel in open state (control)

Trace b: Inhibition of mitoK $\mathrm{ATP}_{\mathrm{AT}}$ by $(0.2 \mathrm{mM})$

Trace c: Activation of mitoK $\mathrm{K}_{\text {ATP }}$ by PMA $(0.2 \mu \mathrm{M})$ in the presence of ATP $(0.2 \mathrm{mM})$ (trace almost superimposing on trace ' $a$ ')

Trace d: Inhibition of PMA activated mito $\mathrm{K}_{\mathrm{ATP}}$ by glibenclamide $(10 \mu \mathrm{M})$ in the presence of ATP (the trace almost superimposes on trace ' $b$ ') 


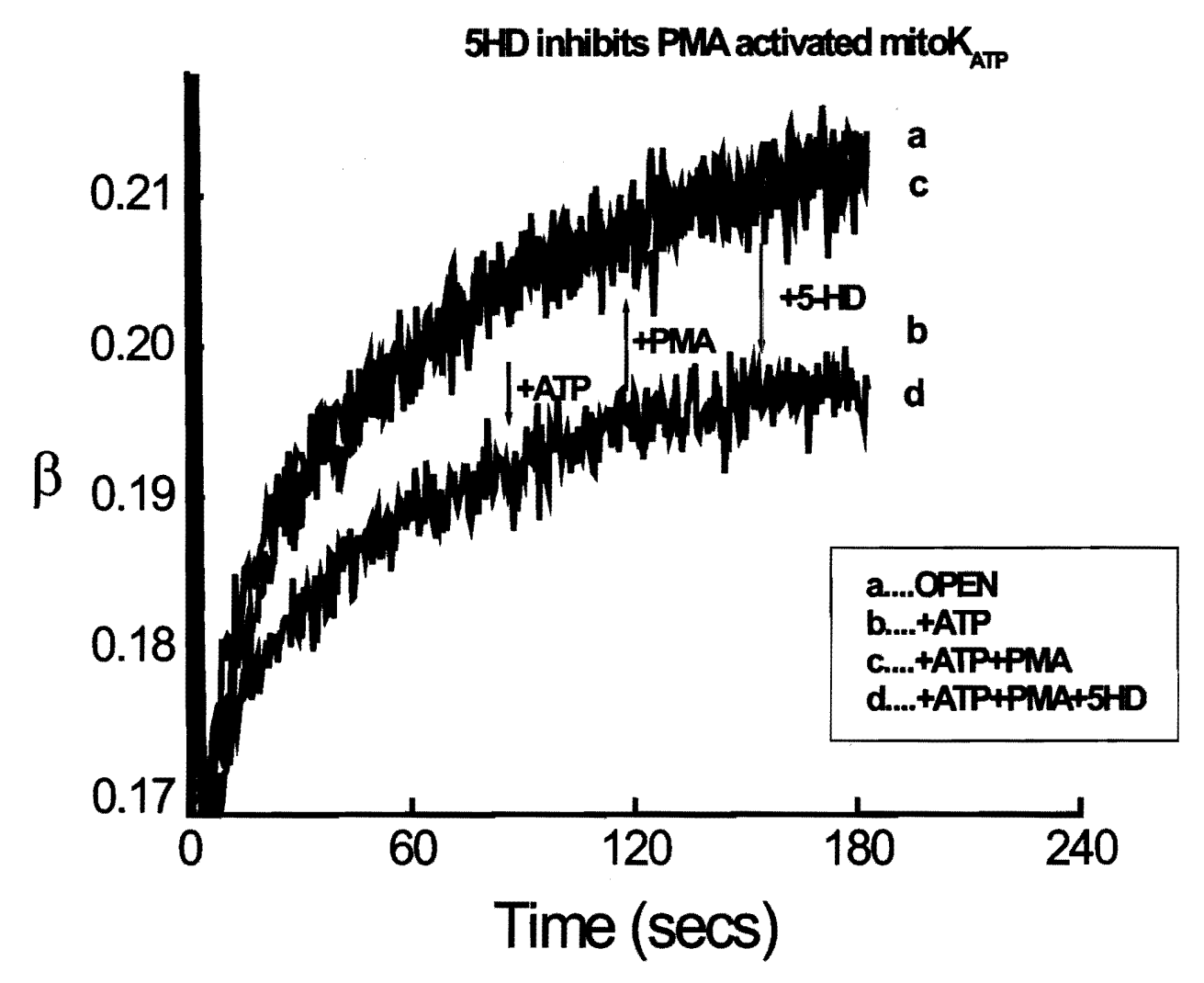

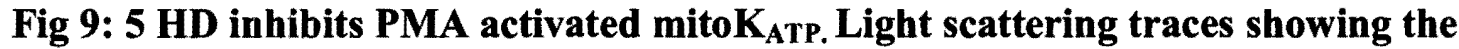
activity of mitoK $K_{A T P}$ in mouse heart mitochondria respiring on succinate supplemented $\mathrm{K}^{+}$medium $(120 \mathrm{mM})$ at $30.5^{\circ} \mathrm{C}$. The light scattering parameter $\beta$, an index of matrix volume, is plotted against time.

Trace a: Resting mitoK $\mathrm{K}_{\mathrm{ATP}}$ channel in open state

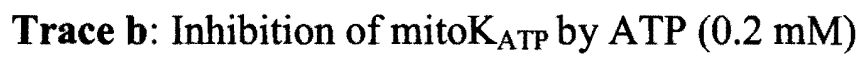

Trace c: Activation of mitoK $\mathrm{ATP}_{\text {by PMA }}(0.2 \mu \mathrm{M})$ in the presence of ATP $(0.2 \mathrm{mM})$ (trace seen almost superimposing trace ' $a$ ')

Trace d: Inhibition of PMA activated mitoK $\mathrm{ATP}_{\text {by }} 5 \mathrm{HD}(300 \mu \mathrm{M})$ in the presence of ATP (the trace almost superimposes on trace ' $b$ ') 


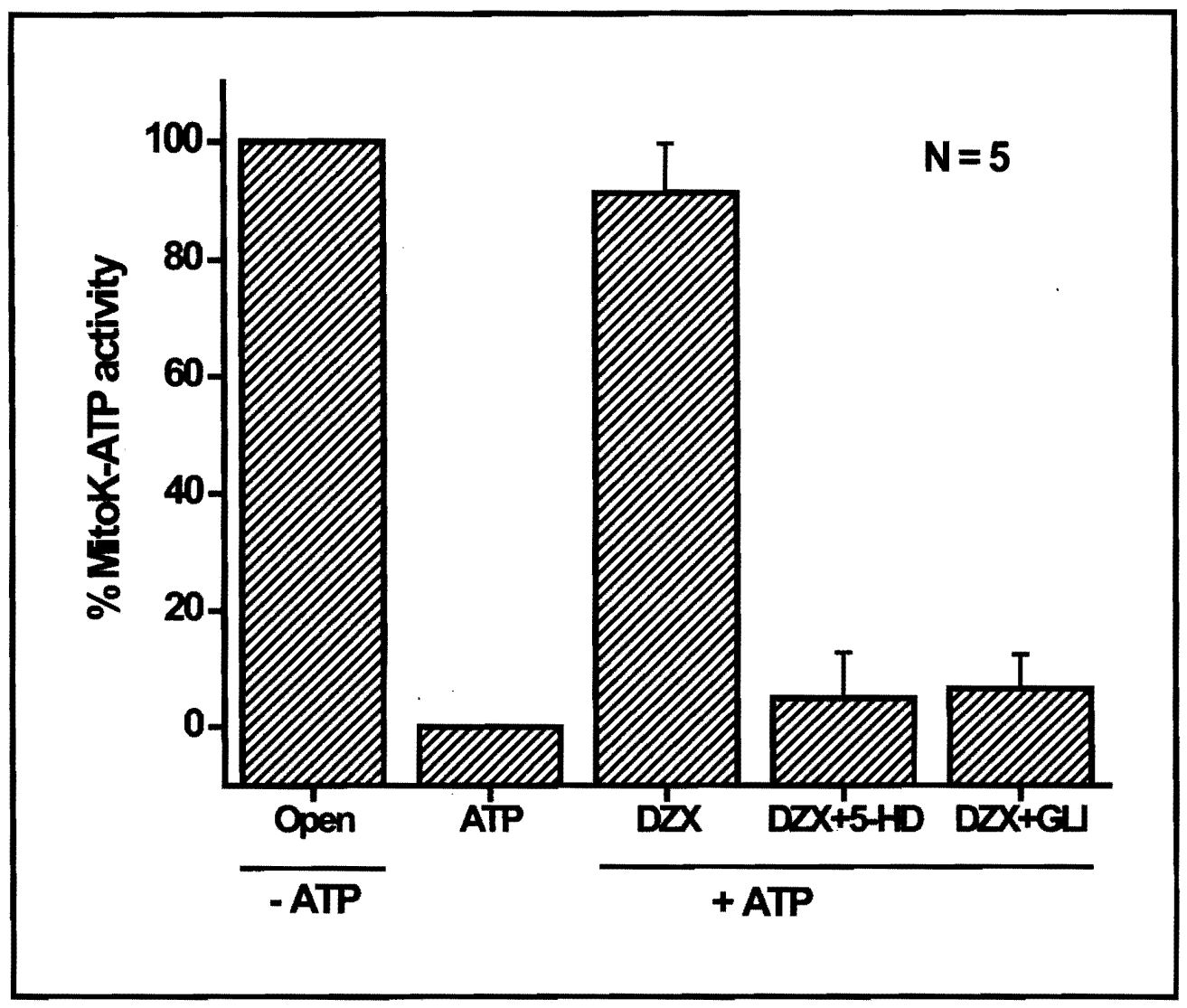

Fig 10: Summarized data for the percentage mitoK $\mathrm{ATP}_{\mathrm{Activity}}$ exhibited by isolated mouse heart mitochondria when subjected to $\mathrm{KCO}$ diazoxide and blockers 5 hydroxydecanoate (5 HD) and glibenclamide. The results summarized are for five independent experiments for each combination. Error bars represent SDs from the average of five individual experiments.

Open: Control traces with no ATP (100\% mitoK ATP $_{\text {activity) }}$

ATP: $\%$ mitoK $_{\text {ATP }}$ activity in the presence of $0.2 \mathrm{mM} \mathrm{ATP}(0 \%)$

DZX: $\%$ mitoK $_{\text {ATP }}$ activity in the presence of $30 \mu \mathrm{M}$ diazoxide $+0.2 \mathrm{mM}$ ATP

DZX+5-HD: $\%$ mitoK $_{\text {ATP }}$ activity with $30 \mu \mathrm{M} \mathrm{DZX+300 \mu M} \mathrm{5-HD+} 0.2$ mM ATP

$\mathrm{DZX}+\mathrm{GLI}: \%$ mitoK $_{\mathrm{ATP}}$ activity with $30 \mu \mathrm{M} \mathrm{DZX}+10 \mu \mathrm{M}$ glibenclamide $+0.2 \mathrm{mM}$ ATP 


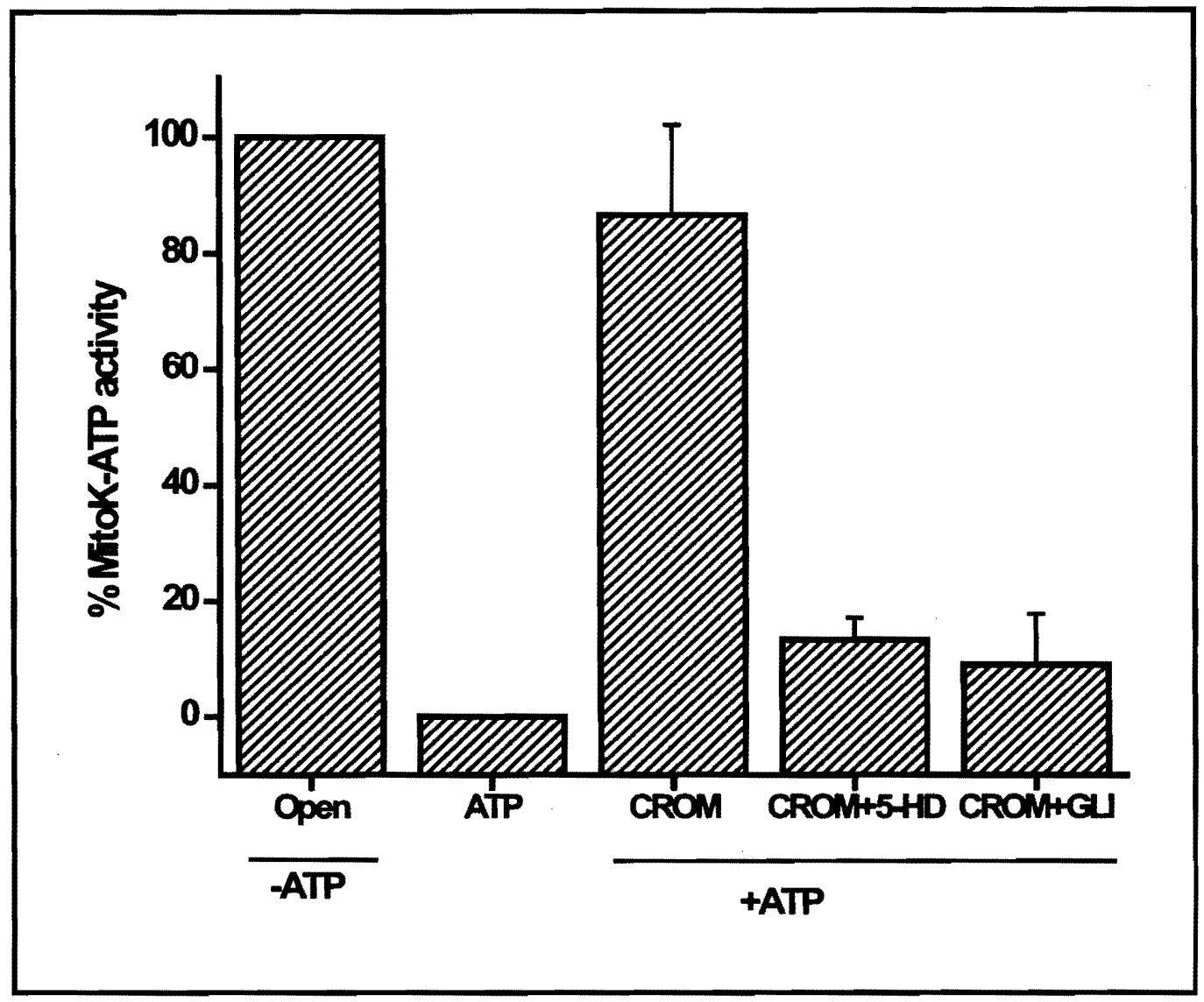

Fig 11: Summarizing the $\%$ mitoK $_{\mathrm{ATP}}$ activity exhibited by isolated mouse heart mitochondria when subjected to cromakalim alone and in combination with 5HD and glibenclamide. The results summarized are for $N=5$ for each combination. Error bars represent SDs from the average of five individual experiments.

Open: Control traces with no ATP $\left(100 \%\right.$ mitoK $_{\text {ATP }}$ activity)

ATP: $\%$ mitoK $_{\text {ATP }}$ activity in the presence of $0.2 \mathrm{mM} \mathrm{ATP}(0 \%)$

CROM: \% mitoK $\mathrm{m}_{\mathrm{ATP}}$ activity in the presence of $50 \mu \mathrm{M}$ cromakalim $+0.2 \mathrm{mM}$ ATP

CROM+5-HD: $\%$ mitoK $_{\text {ATP }}$ activity with $50 \mu \mathrm{M}$ cromakalim+ $300 \mu \mathrm{M} 5-\mathrm{HD}+0.2$ mM ATP

CROM+GLI: $\%$ mitoK $_{\text {ATP }}$ activity with $50 \mu \mathrm{M}$ cromakalim $+10 \mu \mathrm{M}$ glibenclamide + $0.2 \mathrm{mM}$ ATP 


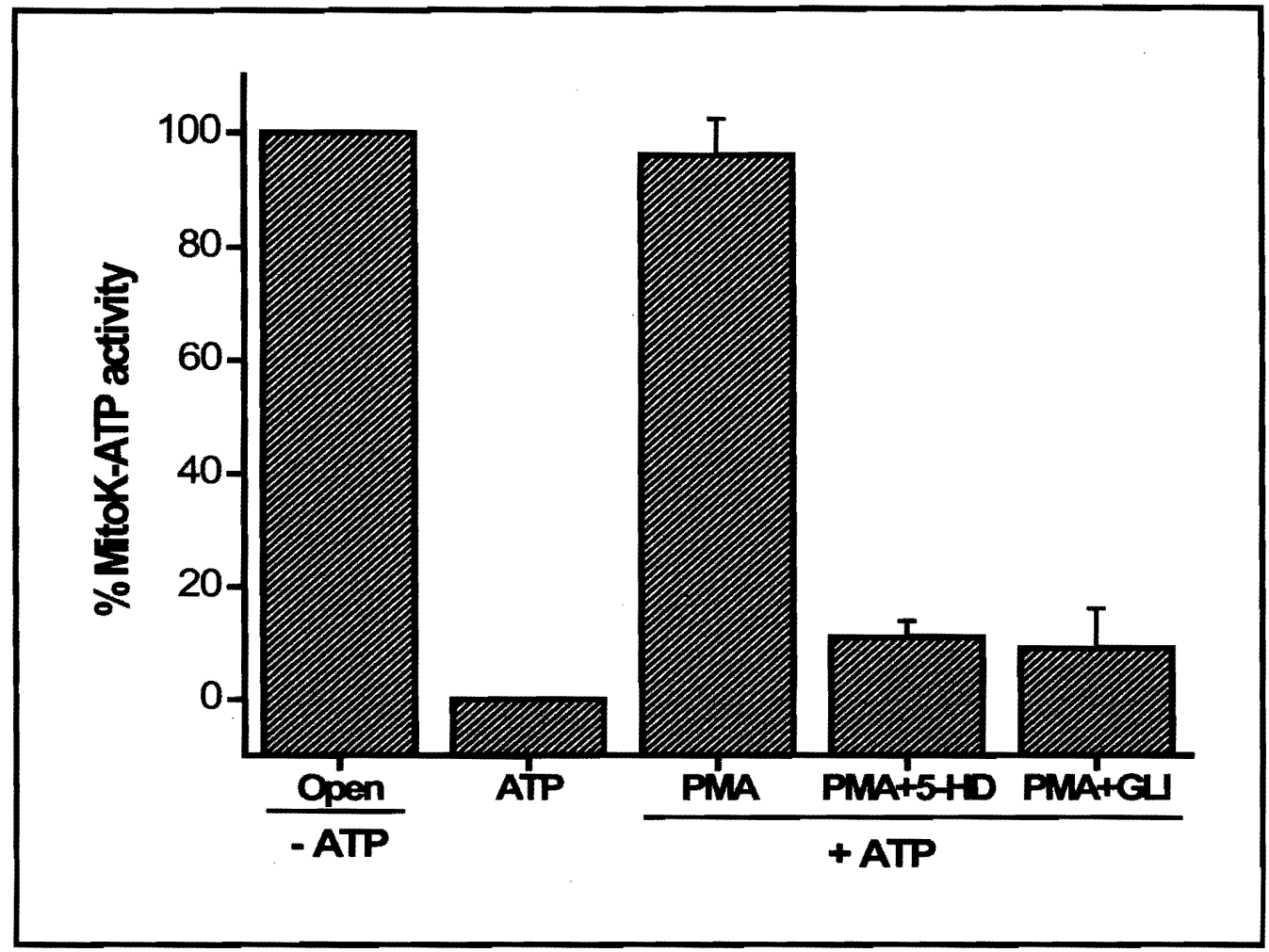

Fig 12: Summarizing the $\%$ mitoK $_{\mathrm{ATP}}$ activity exhibited by isolated mouse heart mitochondria when subjected to PMA alone and in combination with 5-HD and glibenclamide. The results summarized are for $\mathrm{N}=5$ for each combination. Error bars represent SDs from the average of five individual experiments.

Open: Control traces with no ATP $\left(100 \%\right.$ mitoK $_{\text {ATP }}$ activity)

ATP: $\%$ mitoK $_{\text {ATP }}$ activity in the presence of $0.2 \mathrm{mM} \mathrm{ATP}(0 \%)$

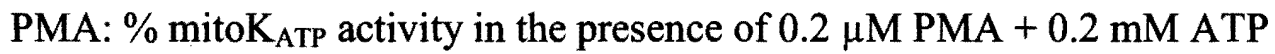

PMA+5-HD: $\%$ mitoK $_{\text {ATP }}$ activity with $0.2 \mu \mathrm{M}$ PMA+ $300 \mu \mathrm{M}$ 5-HD+ $0.2 \mathrm{mM}$ ATP

PMA+GLI: $\%$ mitoK $_{\mathrm{ATP}}$ activity with $0.2 \mu \mathrm{M}$ PMA $+10 \mu \mathrm{M}$ glibenclamide $+0.2 \mathrm{mM}$ ATP 


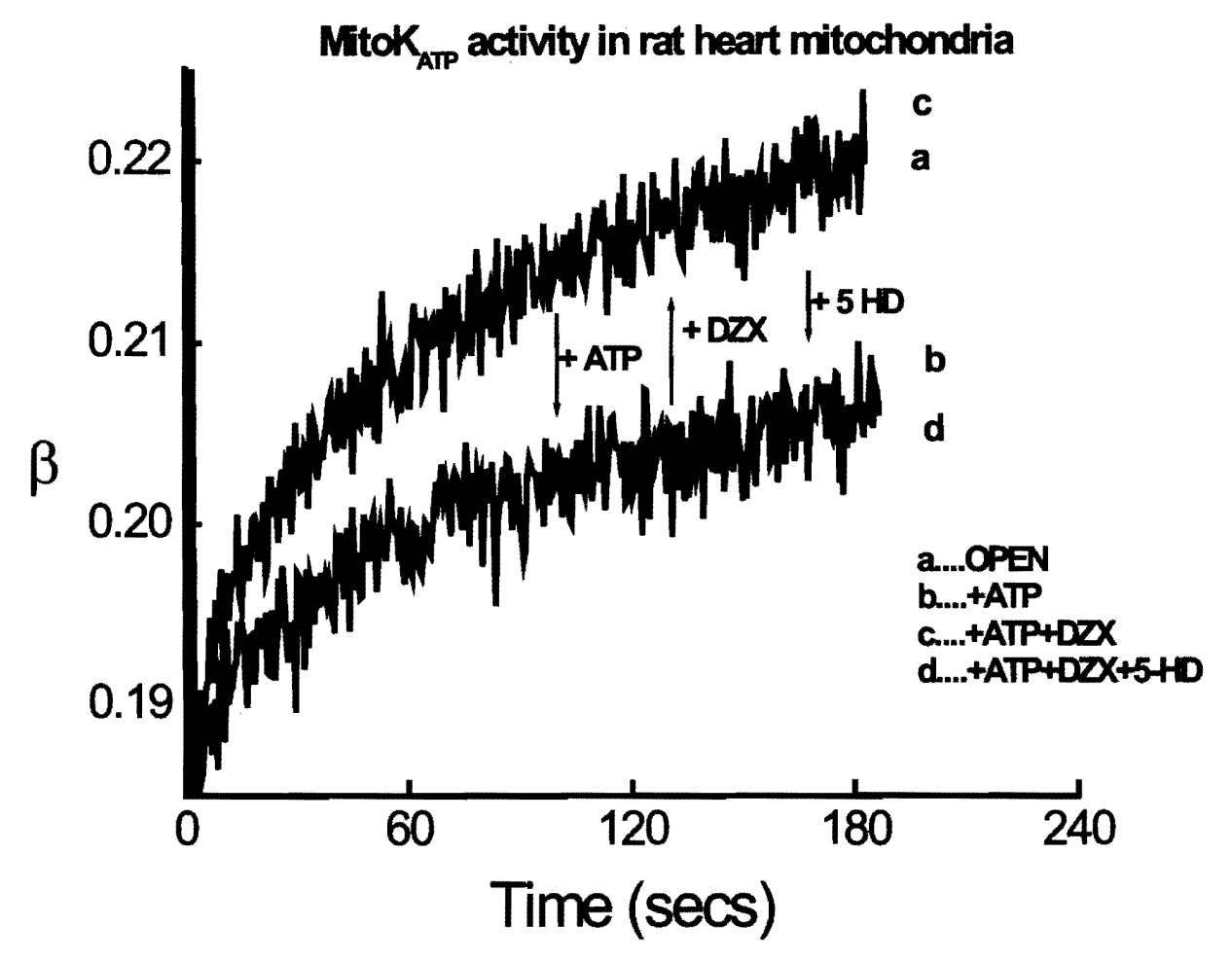

Fig 13: A typical light scattering trace showing the activity of mitoK $\mathrm{K}_{\mathrm{ATP}}$ in rat heart mitochondria under the same experimental conditions i.e., respiring on succinate supplemented $\mathrm{K}^{+}$medium $(120 \mathrm{mM})$ at $30.5^{\circ} \mathrm{C}$. The light scattering parameter $\beta$, an index of matrix volume, is plotted against time.

Trace a: Resting mitoK $\mathrm{ATP}_{\mathrm{P}}$ channel in open state (control/open)

Trace b: Inhibition of mitoK $\mathrm{ATP}_{\text {by ATP }}(0.2 \mathrm{mM})(+\mathrm{ATP})$

Trace c: Activation of mitoK $\mathrm{ATP}_{\mathrm{A}}$ by $\mathrm{KCO}$ diazoxide $(30 \mu \mathrm{M})$ in the presence of ATP

Trace d: Inhibition of activated mitoK $\mathrm{ATP}_{\text {by }} 5 \mathrm{HD}(300 \mu \mathrm{M})$ in the presence of ATP and diazoxide

Note: The results obtained with the combination of diazoxide and 5 HD were reproducible by combining diazoxide + glibenclamide $(10 \mu \mathrm{M})$, cromakalim $(50 \mu \mathrm{M})$ $+5 \mathrm{HD}$ or cromakalim + glibenclamide, and also PMA $(0.2 \mu \mathrm{M})+5$ HD or PMA + glibenclamide. (data not shown) 


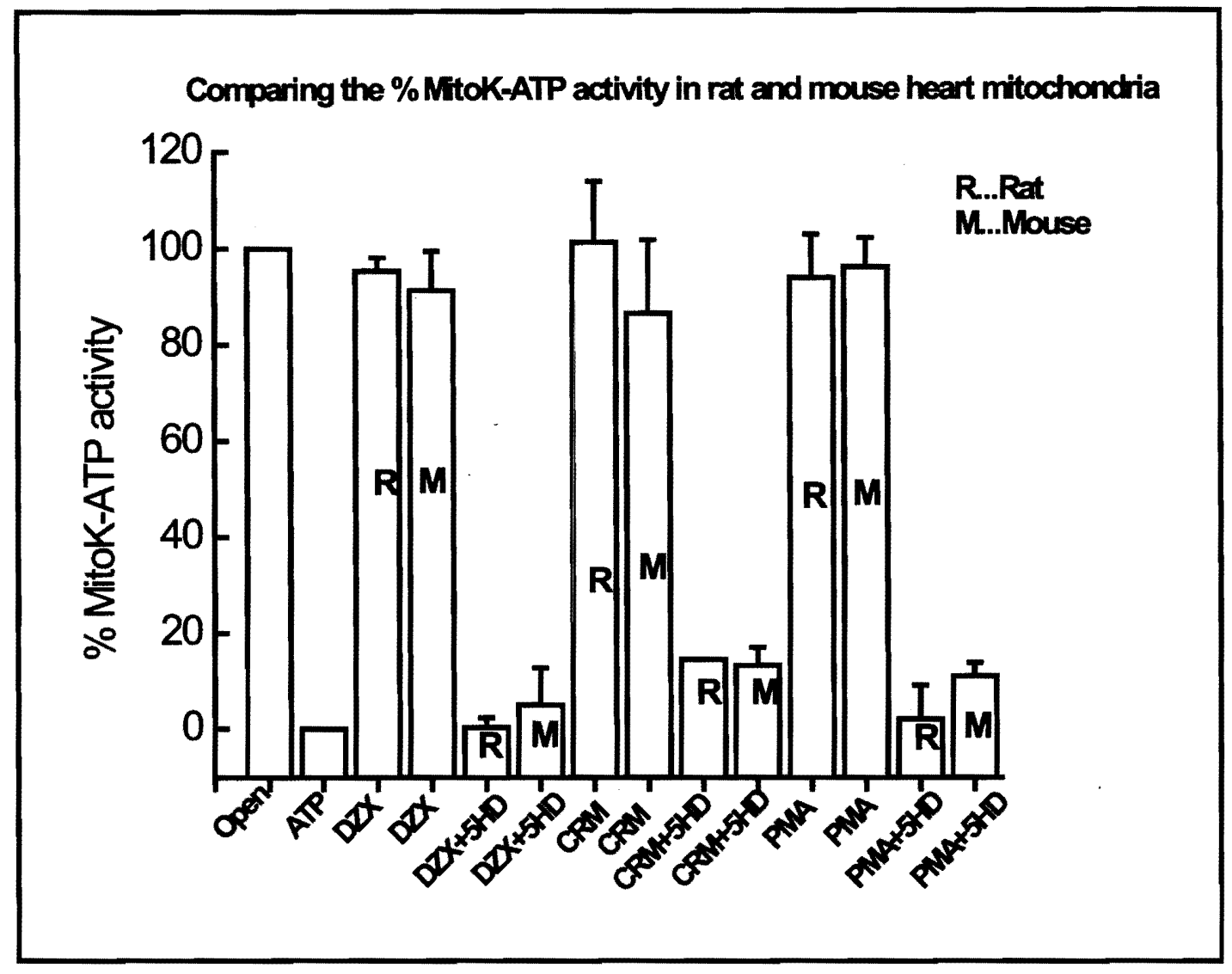

Fig 14: The following figure compares the $\%$ mitoK $_{\text {ATP }}$ activity activity exhibited by both rat and mouse heart mitochondria under the same experimental conditions and in the presence of various potassium channel openers and blockers. Error bars represent SDs from the average of five individual experiments. The rates in the absence of ATP (open) were set as 100\% and in the presence of ATP as $0 \%$. The various openers and blockers are analyzed in relation to these set controls.

- Diazoxide (DZX) has caused a significant reactivation of the mitoK $\mathrm{ATP}_{\mathrm{AT}}$ in both rat and mouse heart mitochondria. This effect is significantly inhibited by $5 \mathrm{HD}$ in both study models.

- The openable effects of cromakalim (CRM) on mitoK $\mathrm{K}_{\mathrm{ATP}}$ are significantly inhibited by $5 \mathrm{HD}$ in both rat and mouse heart mitochondria.

- The activation of mitoK $\mathrm{KTTP}_{\mathrm{A}}$ by PMA is significantly inhibited in the presence of $5 \mathrm{HD}$ in both the study models. 
Fig 15: Chemical structures of $K_{\text {ATP }}$ channel activators

Cromakalim

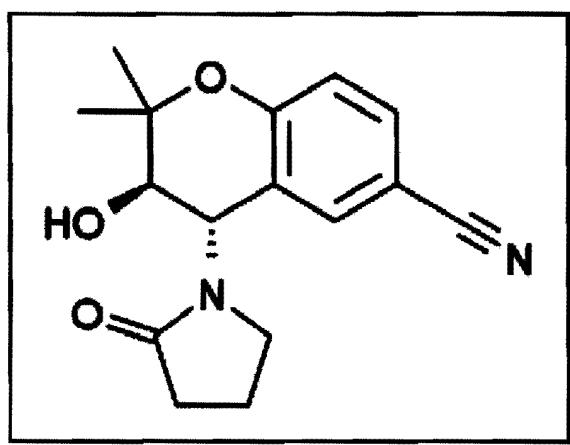

Nicorandil

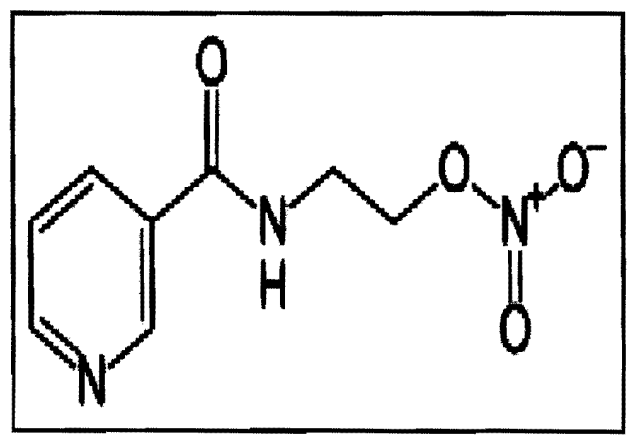

Diazoxide

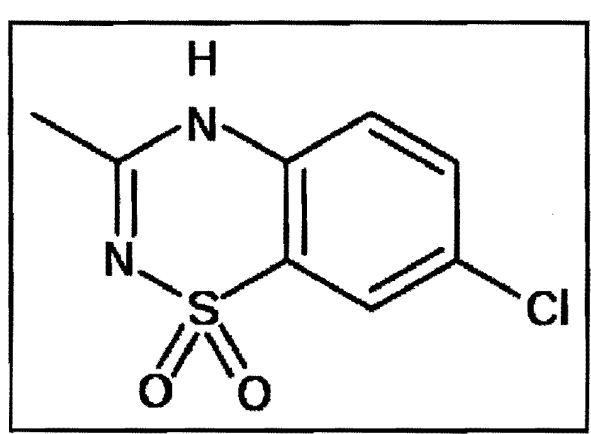

PMA

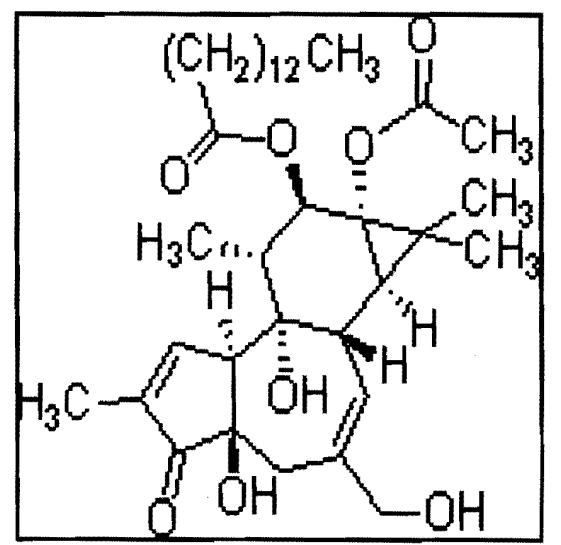


Fig 16: Chemical structures of $K_{\text {ATP }}$ blockers

5 hydroxydecanoate (5 HD)

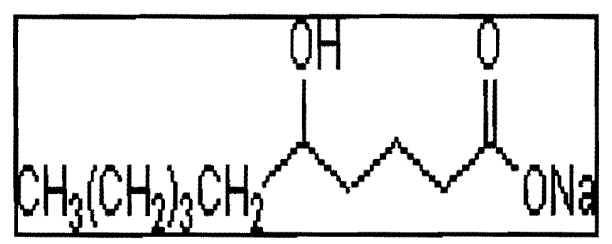

Glibenclamide

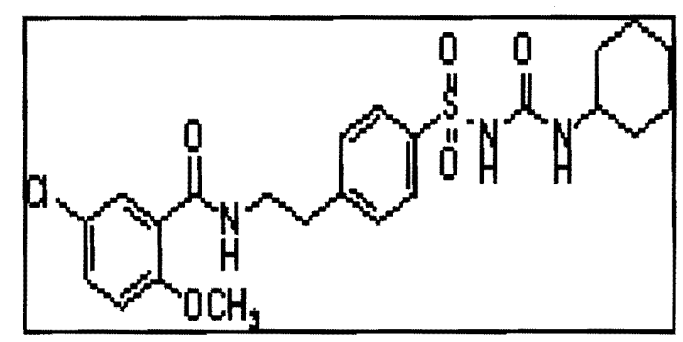

\section{Glyburide}

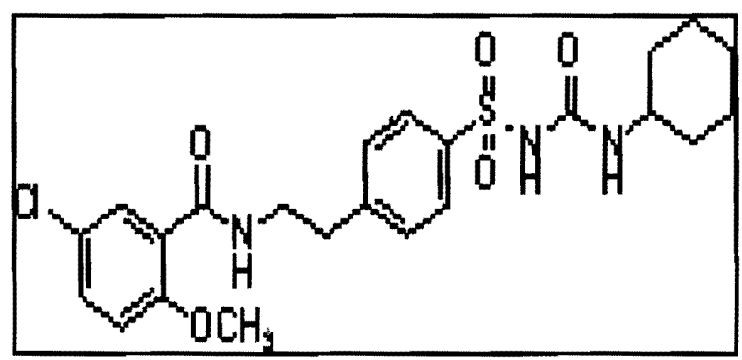




\section{CHAPTER 6}

\section{DISCUSSION:}

Mitochondrial ATP sensitive potassium channels ( mitoK $_{\text {ATP }}$ ) are believed to be integral in the physiology of cardioprotection and cardiac ischemia related manifestations $[46,47,72,77]$. The various cardioprotective drugs such as diazoxide are thought to act through the mitoK $\mathrm{K}_{\mathrm{ATP}}$ and hence involved in cardioprotection, as evidenced by the infarct size post ischemic-preconditioning and ischemia-reperfusion injury $[46,47,51,75,78,82]$.

ATP-sensitive potassium channels $\left(\mathrm{K}_{\text {ATP }}\right)$ are found in a variety of tissues that include pancreatic $\beta$-cells, neurons of brain parenchyma, heart, skeletal and smooth muscle cells [1]. Cardiac cells contain two divergent $K_{\text {ATP }}$ channels, the classical one in the sarcolemma (cellK $\mathrm{ATP}_{\mathrm{AT}}$ [1] and the other in the inner membrane of the mitochondria (mitoK $\left.{ }_{\text {ATP }}\right)[44,73]$. Garlid et al. observed that the mitoK ${ }_{\text {ATP }}$ exhibited several properties comparable to those of the cellK $\mathrm{K}_{\mathrm{ATP}}[45,69,77,90]$

CellK $_{\mathrm{ATP}}$ are implicated in a variety of roles and are implemental in transitioning the metabolic status of a cell into a physiological effect [21, 86, 87, 88, 89]. Kir and SUR subunits, that are heteromultimers, constitute the cellK $\mathrm{K}_{\mathrm{ATP}}[29,31,69,90]$. Kir is believed to assemble with SUR as a 4:4 complex and function as an octameric channel $[29,31,41,42,69,90]$. The SURs are members of the ATP-binding cassette (ABC) family $[29,31,69,77]$. The genes that encode SUR1 and SUR2 are mostly 
homologous, while SUR2A (cardiac) and 2B (smooth muscle) are splice variants [29, $77,90]$. SUR 1 is thought to regulate the pancreatic $\beta$ channel activity, SUR2A the cardiac channel, and SUR 2B the smooth muscle channel [29, 30, 31, 77]. Kir channels are tetramers and have two transmembrane domains linked by a pore loop. $[29,30,31,37,77]$

The subunits that configure the mitoK $\mathrm{K}_{\mathrm{ATP}}$ are thought to be qualitatively equivalent to the cell $\mathrm{K}_{\text {ATP }}[77,90]$. The activity of mitoK $\mathrm{K}_{\mathrm{ATP}}$ is modulated by various biochemical and pharmacological agents, some reacting with mitoSUR (mitochondrial sulfonylurea receptor), and others with mitoKir (mitochondrial inward rectifying potassium channel receptor) [Fig 2] $[77,78,90]$. Garlid et al. showed that mitoK $\mathrm{ATP}_{\mathrm{P}}$ is a high affinity receptor for $\mathrm{K}^{+}$channel openers (KCOs), including cromakalim, diazoxide and PMA (a PKC $\varepsilon$ activator), and this activation is inhibited in the presence of $5 \mathrm{HD}$ and glibenclamide. $[46,47,48,72,75,90]$

Through my experiments I have tried to characterize the activity of mitoK $\mathrm{ATP}_{\mathrm{A}}$ in the mitochondria of control mouse by testing the activity of this channel in the presence of various specific and non-specific potassium channel openers and their blockers. It was evident from my results that the channel was significantly active in the mouse heart mitochondria. The light scattering traces initiated in the presence of various KCOs and their inhibitors showed results that were comparable to those in the rat heart mitochondria [Fig $13 \& 14]$. The various selective and non-selective activators and 
inhibitors of the channel exhibited their activity at a concentration that was identical to that used for the rat heart mitochondria. Diazoxide, a selective $\mathrm{KCO}$ activated the channel in $30 \mu \mathrm{M}$ range, a concentration at which a significant channel activity was witnessed in rat heart. This activator effect of diazoxide was inhibited by 5 HD ( 300 $\mu \mathrm{M})$ and glibenclamide $(10 \mu \mathrm{M})$. Cromakalim, a non-selective $\mathrm{KCO}$ demonstrated significant channel opening when added as a $50 \mu \mathrm{M}$ final concentration. The channel activity was inhibited by both $5 \mathrm{HD}$ and glibenclamide. Phorbol 12-myristate-13acetate (PMA), which is a PKC $\varepsilon$ (Protein Kinase $\mathrm{C}$ epsilon) activator, caused a significant activation of the mitoK $\mathrm{K}_{\mathrm{ATP}}$ in the $0.2 \mu \mathrm{M}$ range; an effect that was inhibited by 5 -hydroxydecanoate ( $5 \mathrm{HD}$ ). Channel activity was evident considering and comparing the rates of various light scattering traces initiated.

The mitoK $\mathrm{ATP}_{\mathrm{AT}}$ activity, having been characterized in control mouse heart mitochondria, would eventually be an ideal platform to explore further the structural

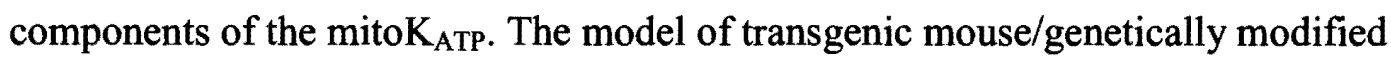
mouse, powered with the light scattering technique and immunological tools such as western blots and immunoflorescence techniques, would be one of the most ideal and logistic extensions in identifying and establishing the subunit assembly of the mitoK $_{\text {ATP. }}$ Also, from the data analysis it seems evident that the mitoK $\mathrm{ATP}_{\text {activity }}$ exhibited by control mouse heart mitochondria is similar and comparable to that exhibited by the rat heart mitochondria considering the channel activity exhibited in the presence of various potassium channel openers and their blockers. The data 
validates the use of the mouse as a comprehensive study model for the analysis of mitoK $_{\text {ATP }}$ activity in the heart mitochondria. 


\section{REFERENCES:}

1. Noma, A. (1983) ATP-regulated $\mathrm{K}^{+}$channels in cardiac muscle. Nature 305 , $147-148$.

2. Cook, D. L., and Hales, C. N. (1984) Intracellular ATP directly blocks $\mathrm{K}^{+}$ channels in pancreatic $\beta$-cells. Nature 311, 271-273.

3. Ashcroft, F. M., Harrison, D. E., and Ashcroft, S. J. H. (1984). Glucose induces closure of single potassium channels in isolated rat pancreatic $\beta$-cells. Nature $312,446-448$.

4. Spruce, A. E., Standen, N. B., and Standfield, P. R. (1985). Voltage dependent ATP-sensitive potassium channels of skeletal muscle membrane. Nature 316 , 736-738.

5. Standen, N. B., Quayle, J. M., Davis, N. W., Brayden, J. E., Huang, Y., and Nelson, M. T. (1989) Hyperpolarizing vasodilators activate ATP-sensitive $\mathrm{K}^{+}$ channels in arterial smooth muscle. Science 245, 177- 180.

6. Ashford, M. L. J., Sturgess, N. C., Trout, N. J., Gardner, N. J., and Hales, C. N. (1988) Adenosine-5'-triphosphate-sensitive ion channels in neonatal rat cultured central neurons. Pfluigers Arch. 412, 297-304.

7. Ashcroft, S. J. H., and Ashcroft, F. M. (1990) Properties and function of ATPsensitive K-channels. Cell. Signaling 2, 197-214. 
8. Terzic, A., Jahangir, A., and Kurachi, Y. (1995) Cardiac ATP-sensitive $\mathrm{K}^{+}$ channels: regulation by intracellular nucleotides and $\mathrm{K}^{+}$channel-opening drugs. Am. J. Physiol. 269, C525-C545.

9. Nelson, M. T., and Quayle, J. M. (1995) Physiological roles and properties of potassium channels in arterial smooth muscle. Am. J. Physiol. 268, C799C822.

10. Dunne, M. J., and Petersen, O.H. (1986) GTP and GDP activation of $\mathrm{K}^{+}$ channels that can be inhibited by ATP. Pflugers Arch. 407, 564-565.

11. Weiss, J. N., Venkatesh, N., and Lamp, S. T. (1992) ATP-sensitive $\mathrm{K}^{+}$ channels and cellular $\mathrm{K}+$ loss in hypoxic and ischemic mammalian ventricle. J. Physiol. Lond. 447, 649-673.

12. Lazdunski, M. (1994) ATP-sensitive potassium channels: an overview. J. Cardiovasc. Pharmacol. 24, S1-S5.

13. Quast, U., and Cook, N. S. (1989) In vitro and in vivo comparison of two $\mathrm{K}^{+}$ channel openers, diazoxide and cromakalim and their inhibition by glibenclamide. J. Pharmacol. Exp. Ther. 250, 261-271.

14. Trube, G., and Hescheler, J. (1984) Inward-rectifying channels in isolated patches of the heart cell membrane: ATP-dependence and comparison with cell-attached patches. Pflugers Arch. 401, 178- 184.

15. Findlay, I. (1986) ATP maintains ATP-inhibited channels in an operational state. Pflugers Arch. 407, 238-240. 
16. Ohno-Shosaku, T., ZiinMer, B. J., and Trube, G. (1987) Dual effects of ATP on $\mathrm{K}^{+}$currents of mouse pancreatic $\beta$-cells. Pflugers Arch. 408, 133-138.

17. Takano, M., Qin, D., and Noma, A. (1990) ATP-dependent decay and recovery of $\mathrm{K}^{+}$channels in guinea pig cardiac myocytes. Am. J. Physiol. 258, H45-H50.

18. Gribble, F. M., Tucker, S. J., Haug, T., and Ashcroft, F. M. (1998) MgATP activates the $\beta$-cell KATP channel by interaction with its SUR1 subunit. Proc. Natl. Acad. Sci. U.S.A. 95, 7185-7190.

19. Grover, G. J., McCullough, J. R., Henry, D. E., Conder, M. L., and Sleph, P. G. (1989) Anti-ischemic effects of the potassium channel activators pinacidil and cromakalirn and the reversal of these effects with the potassium channel blocker glyburide. J. Pharmacol. Exp. Ther. 251, 98-104.

20. Grover, G. J. (1994) Protective effects of ATP-sensitive potassium-channel openers in experimental myocardial ischemia. J. Cardiovasc. Pharmacol. 24, S18-S27.

21. Nichols, C. G., and Lederer, W. J. (1991) Adenosine triphosphate-sensitive potassium channels in the cardiovascular system. Am. J. Physiol. 261, H16751686.

22. Garrino, M. G., Plant, T. D., and Henquin, J. C. (1989) Effects of putative activators of $\mathrm{K}^{+}$channels in mouse pancreatic $\beta$-cells. Br. J. Pharmacol. 98, 957-965. 
23. Zunkler, B. J., Lenzen, S., Manner, K., Panten, U., and Trube, G. (1988). Concentration-dependent effects of tolbutamide, meglitinide, glipizide, glibenclamide and diazoxide on ATP-regulated $\mathrm{K}^{+}$currents in pancreatic $\beta$ cells. Naunyn. Schmiedebergs. Arch. Pharmacol. 337, 225-230.

24. Misler, S., Gee, W. M., Gillis, K. D., Scharp, D. W., and Falke, L. C (1989). Metabolite-regulated ATP-sensitive $\mathrm{K}^{+}$channel in human pancreatic islet cells. Diabetes 38, 422-427.

25. Henquin, J. C., and Meissner, H. P. (1982). Opposite effects of tolbutamide and diazoxide on ${ }^{86} \mathrm{Rb}^{+}$fluxes and membrane potential in pancreatic $\beta$-cells. Biochem. Pharmacol. 31, 1407-1415.

26. Dunne, M. J., and Petersen, O. H. (1991) Potassium selective ion channels in insulin-secreting cells: pharmacology and their role in stimulus-secretion coupling. Biochim. Biophys. Acta 1071, 67-82.

27. Inagaki, N., Tsuura, Y., Namba, N., Masuda, K., Gonoi, T., Horie, M., Seino, Y., Mizuta, M., and Seino, S. (1995) Cloning and functional characterization of a novel ATP-sensitive potassium channel ubiquitously expressed in rat tissues, including pancreatic islets, pituitary, skeletal muscle, and heart. J. Biol. Chem. 270, 5691-5694.

28. Nichols, C. G., and Lopatin, A. N. (1997) Inward rectifier potassium channels. Annu. Rev. Physiol. 59, 171- 191. 
29. Inagaki, N., Gonoi, T., Clement, J. P., IV, Wang, C.-Z., Aguilar-Bryan, L., Bryan, J., and Seino, S. (1996). A family of sulfonylurea receptors determines the pharmacological properties of ATP-sensitive $\mathrm{K}^{+}$channels. Neuron 16 , 1011-1017.

30. Isomoto, S., Kondo, C., Yamada, M,, Matsumoto, S., Higashiguchi, O., Horio, Y., Matsuzawa, Y., and Kurachi, Y. (1996) A novel sulfonylurea receptor forms with BIR (Kir6.2) a smooth muscle type ATP-sensitive $\mathrm{K}^{+}$ channel. J. Biol. Chem. 271, 24321-24324.

31. Aguilar-Bryan, L., Nichols, C. G., Wechsler, S. W., Clement, J. P., IV, Boyd, A. E., III, Gonzalez, G., Herrera-Sosa, H., Nguy, K., Bryan, J., and Nelson, D. A. (1995) Cloning of the $\beta$ cell high-affinity sulfonylurea receptor: a regulator of insulin secretion. Science 268, 423-426.

32. Higgins, C. F. (1995) The ABC of channel regulation. Cell 82, 693-696.

33. Tusnady, G. E., Bakos, E., Varadi, A., and Sarkadi, B. (1997) Membrane topology distinguishes a subfamily of the ATP-binding cassette (ABC) transporters. FEBS Lett. 402, 1-3.

34. Inagaki, N., Gonoi, T., Clement IV, J. P., Namba, N., Inazawa, J., Gonzalez, G., Aguilar-Bryan, L., Seino, S., and Bryan, J. (1995) Reconstitution of IKATP; an inward rectifier subunit plus the sulfonylurea receptor. Science $270,1166-$ 1170. 
35. Sakura, H., Ammala, C., Smith, F. M., Gribble, F. M., and Ashcroft, F. M. (1995). Cloning and functional expression of the cDNA encoding a novel ATP-sensitive potassium channel subunit expressed in pancreatic $\beta$-cells, brain, heart, and skeletal muscle. FEBS Lett., 377, 338-344.

36. Tucker S. J., Gribble, F. M., Zhao C., Trapp, S., and Ashcroft, F. M. (1997) Truncation of Kir6.2 produces ATP-sensitive $\mathrm{K}+$ channels in the absence of the sulfonylurea receptor. Nature $387,179-183$.

37. Aguilar-Bryan, L., Nelson, D. A., Vu, Q. A., Humphrey, M. B., and Boyd, A. E., III (1990) Photoaffinity labeling and partial purification of the $\beta$ cell sulfonylurea receptor using a novel, biologically active glyburide analog. J. Biol. Chem. 265, 8218-8224.

38. Thomas, P. M., Cote, G. J., Wohlik, N., Haddad, B., Mathew, P. M., Rabl, W., Aguilar-Bryan, L., Gagel, R. F., and Bryan, J. (1995) Mutations in the sulfonylurea receptor gene in familial persistent hyperinsulinemic hypoglycemia of infancy. Science $268,426-429$.

39. Thomas, P. M., Wohllk, N., Huang, E., Kuhnle, U., Rabl, W., Gagel, R. F., and Cote, G. J. (1996) Inactivation of the first nucleotide-binding fold of the sulfonylurea receptor, and familial persistent hyperinsulinemic hypoglycemia of infancy. Am. J. Hum. Genet. 59, 510-518. 
40. Gribble, F. M., Tucker, S. J., and Ashcroft, F. M. (1997) The essential role of the Walker A motifs of SURl in K-ATP channel activation by Mg-ADP and diazoxide. EMBO J. 16, 1145-1152.

41. Clement, J. P., N, Kunjilwar, K., Gonzalez G., Schwanstecher, M., Panten, U., Aguilar-Bryan, L., and Bryan, J. (1997) Association and stoichiometry of $\mathrm{K}_{\mathrm{ATP}}$ channel subunits. Neuron $18,827-838$.

42. Inagaki, N., Gonoi, T., and Seino, S. (1997) Subunit stoichiometry of the pancreatic $\beta$-cell ATP-sensitive $\mathrm{K}^{+}$channel. FEBS Lett. 409, 232-236.

43. Shyng, S., and Nichols, C. G. (1997) Octameric stoichiometry of the KATP channel complex. J. Gen. Physiol. 110, 655-664.

44. Inoue, I., Nagase, H., Kishi, K., and Higuti, T. (1991) ATP-sensitive K channel in the mitochondrial inner membrane. Nature 352, 244-247.

45. Paucek, P., Mironova, G., Mahdi, F., Beavis, A. D., Woldegiorgis, G., and Garlid, K. D. (1992) Reconstitution and partial purification of the glibenclamide-sensitive, ATP-dependent $\mathrm{K}^{+}$channel from rat liver and beef heart mitochondria. J. Biol. Chem. 267, 26062-26069.

46. Garlid, K. D., Paucek, P., Yarov-Yarovoy, V., Sun, X., and Schindler, P. A. (1996). The mitochondrial $\mathrm{K}_{\mathrm{ATP}}$ channel as a receptor for potassium channel openers. J. Biol. Chem. 271, 8796-8799.

47. Garlid, K. D., Paucek, P., Yarov-Yarovoy, V., Murray, H. N., Darbenzio, R. B., D'Alonzo, A. J., Lodge, N. J., Smith, M. A, and Grover, G. J. (1997) 
Cardioprotective effect of diazoxide and its interaction with mitochondrial ATP-sensitive $\mathrm{K}+$ channels: possible mechanism of cardioprotection. Circ.Res. 81, 1072-1082.

48. Jaburek, M., Yarov-Yarovoy, V., Paucek, P., and Garlid, K. D. (1998) State dependent inhibition of the mitochondrial $\mathrm{K}_{\mathrm{ATP}}$ channel by glyburide and 5hydroxydecanoate. J. Biol. Chem. 273, 13578- 13582.

49. Garlid, K. D. (1988) Mitochondrial volume control. In Integration of Mitochondrial Function (Lemasters, J. J., Hackenbrock, C. R., Thurman, R. G., and Westerhoff, H. V., eds.), pp. 257-276, Plenum Publishing Corp., New York.

50. Garlid, K. D. (1980). On the mechanism of regulation of the mitochondrial $\mathrm{K}^{+} / \mathrm{H}^{+}$exchanger. J. Biol. Chem. 255, 11273- 11279.

51. Garlid, K. D. (1996). Cation transport in mitochondria-the potassium cycle. Biochim. Biophys. Acta 1275, 123-126.

52. Mitchell, P. (1961) Coupling of phosphorylation to electron and hydrogen transfer by a chemi-osmotic type of mechanism. Nature 191, 144-148.

53. Yellon, D. M., Baxter, G. F., Garcia-Dorado, D., Heusch, G., and Sumeray, M. S. (1998) Ischaemic preconditioning: present position and future directions. Cardiovasc. Res. 37, 21-33.

54. Edwards, G., and Weston, A. H. (1993) The pharmacology of ATP-sensitive potassium channels. Annu. Rev. Pharmacol. Toxicol. 33, 597-637. 
55. McCullough, J. R., Normandin, D. E., Conder, M. L., Sleph, P. G., Dzwonczyk, S., and Grover, G. J. (1991) Specific block of the anti-ischemic actions of cromakalim by sodium 5-hydroxydecanoate. Circ. Res. 69, 949958.

56. Gross, G. J., Yao, Z., and Auchampach, J. A. (1994) Role of ATP-sensitive potassium channels in ischemic preconditioning. In Ischemic Preconditioning: The Concepts of Endogenous Cardioprotection (Przyklenk, K., Kloner, R. A., eds.) Developments in Cardiovascular Medicine, Vol. 148, pp. 125-135, Kluwer Academic Publishers, Boston, Mass.

57. Yao, Z., and Gross, G. J. (1994) Effects of the $\mathrm{K}_{\mathrm{ATP}}$ channel opener bimakalim on coronary blood flow, monophasic action potential duration, and infarct size in dogs. Circulation 89, 1769-1775.

58. Grover, G. J., D'Alonzo, A. J., Parham, C. S., and Darbenzio, R. B. (1995) Cardioprotection with the $\mathrm{K}_{\mathrm{ATP}}$ opener cromakalim is not correlated with ischemic myocardial action potential duration. J. Cardiovasc. Pharmacol. 26, $145-152$.

59. Liu, Y., Sato, T., O'Rourke, B., and Marban, E. (1998) Mitochondria1 ATPdependent potassium channels: novel effectors of cardioprotection?

Circulation 97, 2463-2469.

60. Sato, T., O'Rourke, B., and Marban, E. (1998) Modulation of mitochondrial ATP-dependent $\mathrm{K}^{+}$channels by protein kinase C. Circ. Res. 83, 110-114. 
61. Liu, Y., Ytrehus, K., and Downey, J. M. (1998) Evidence that translocation of protein kinase $\mathrm{C}$ is a key event during ischemic preconditioning of rabbit myocardium. J. Mol. Cell. Cardiol. 26, 661-668.

62. Speechly-Dick, M. E., Mocanu, M. M., and Yellon, D. M. (1994) Protein kinase C. Its role in ischemic preconditioning in the rat. Circ. Res. 75, 586590.

63. Ytrehus, K., Liu, Y., and Downey, J. M. (1994) Preconditioning protects ischemic rabbit heart by protein kinase $\mathrm{C}$ activation. Am. J. Physiol. 266, H1145-H1152.

64. Downey, J. M., and Cohen, M. V. (1997). Signal transduction in ischemic preconditioning. Adv. Exp. Med. Biol. 430, 39-55.

65. Garlid, K. D., Paucek, P., and Yarov-Yarovoy, V. (1996) Regulation of the mitochondrial $\mathrm{K}_{\mathrm{ATP}}$ channel by palmitoyl-CoA, adenine and guanine nucleotides, and $\mathrm{K}^{+}$channel openers. Biophys. J. 70, A311.

66. Paucek, P., Yarov-Yarovoy, V. and Garlid, K. D. (1997) Sulfonylurea receptor of the mitochondrial $\mathrm{K}_{\mathrm{ATP}}$ channel. Biophys. J. 72, A39.

67. Paucek, P., Yarov-Yarovoy, V., and Garlid, K. D. (1998) Photoaffinity labeling and purification of mitoSUR, the sulfonylurea receptor of the mitochondrial $\mathrm{K}_{\mathrm{ATP}}$ channel. J. Biol. Chem. submitted. 
68. Szewczyk, A., Wojcik, G., Lobanov, N. A., and Nalecz, M. J. (1997). The mitochondrial sulfonylurea receptor: identification and characterization. Biochem. Biophys. Res. Comm. 230, 611-615.

69. Mironova, G. D., Skarga, Yu. Yu. Grigoriev, S. M., Yarov-Yarovoy, V. M., Alexandrov, A. V., and Kolomytkin, 0. V. (1996). The mitochondrial potassium channel from rat liver mitochondria. 1. Isolation, purification, and reconstitution in a bilayer lipid membrane. Membr. Cell Biol. 10, 429-437.

70. Yarov-Yarovoy V, Paucek P, Jaburek M, Garlid KD. The nucleotide regulatory sites on the mitochondria $\mathrm{K}_{\mathrm{ATP}}$ channel face the cytosol. Biochim Biophys Acta. 1997; 1321:128-136.

71. Beavis, A.D., Brannan, R.D., Garlid, K.D. (1985) Swelling and Contraction of the Mitochondrial Matrix: A structural interpretation of the relationship between light scattering and matrix volume. The Journal of Biological Chemistry 260, 1346-13433.

72. Garlid, K.D., et al., Mitochondrial potassium transport: the role of the mitochondrial ATP - Sensitive $\mathrm{K}^{+}$channel in cardiac function and cardioprotection. Biochem Biophys Acta, 2003. 1606 (1-3): p. 1-21

73. Inoue, I., Nagase, H., Kishi, K. and Higuti, T. (1991) ATP-sensitive K+ channel in the mitochondrial inner membrane. Nature 352, 244-247.

74. G.D. Mironova, N.I. Fedotcheva, P.R. Makarov, L.A. Pronevich, G.P. Mironov, Protein from beef heart mitochondria inducing the potassium 
channel conductivity of bilayer lipid membrane, Biophysik (USSR) 26 (1981) $458-465$.

75. Costa $A D$, et al. (2005) Protein kinase $G$ transmits the cardioprotective signal from cytosol to mitochondria. Circ Res 97:329-336.

76. Tucker, S.J., et al., Truncation of Kir6.2 produces ATP-sensitive $\mathrm{K}^{+}$channels in the absence of the sulphonylurea receptor. Nature, 1997. 387(6629): p. 179183.

77. Garlid, K.D., Paucek P. (2003). Mitochondrial potassium transport: the $\mathrm{K}^{+}$ cycle. Biochemica et Biophysica Acta 1606, 22-41

78. Costa ADT, Pierre SV, Cohen MV, Downey JM, Garlid KD. cGMP signaling in pre- and post-conditioning: the role of mitochondria. Cardiovasc Res2008; 77: 344-352.

79. Grover, G.J.; D’Alonzo, A.J.; Garlid, K.D.; Bajgar, R.; Lodge, N.J.; Sleph, P.G.; Darbenzio, R.B.; Hess, T.A.; Smith, M.A.; Paucek, P.; Atwal, K.S. J. Pharmacol. Exp. Ther., 2001, 297, 1184

80. Mannhold, R. Med. Res. Rev., 2004, 24, 213.

81. Gogelein, H.; Ruetten, H.; Albus, U.; Englert, H.C.; Busch, A.E. Naunyn Schiedebergs Arch. Pharmacol., 2001, 364, 33.

82. L. Testai, S. Rapposelli and V. Calderone. Cardiac ATP-Sensitive Potassium Channels: A Potential Target for an Anti-Ischemic Pharmacological Strategy. 
Cardiovascular \& Hematological Agents in Medicinal Chemistry, 2007, 5, 7990.

83. Halestrap, A. P. (1994) Regulation of mitochondrial metabolism through changes in matrix volume. Biochem. Soc. Trans. 22, 522-529.

84. Costa AD, Quinlan CL, Andrukhiv A, West IC, Jaburek M, Garlid KD. The direct physiological effects of mitoKATP opening on heart mitochondria. Am J Physiol Heart Circ Physiol. 2006; 290: H406-H415.

85. J.M. Quayle, M.T. Nelson, N.B. Standen, ATP-sensitive and inwardly rectifying potassium channels in smooth muscle, Physiol.Rev. 77 (1997) $1165-1232$.

86. R. Paulissian, Diazoxide, Int. Anesthesiol. Clin. 16 (1978) 201-237.

87. F.M. Ashcroft, F.M. Gribble, ATP-sensitive $\mathrm{K}^{+}$channels and insulin secretion: their role in health and disease, Diabetologia 42 (1999) 903-919.

88. G.J. Grover, J.R. McCullough, D.E. Henry, M.L. Conder, P.G.Sleph, Antiischemic effects of the potassium channel activators pinacidil and cromakalim and the reversal of these effects with the potassium channel blocker glyburide, J. Pharmacol. Exp. Ther. 251(1989) 98-104.

89. C.G. Nichols, W.J. Lederer, Adenosine triphosphate-sensitive potassium channels in the cardiovascular system, Am. J. Physiol. 261 (1991) H1675H1686. 
90. Mironova, G. D., Negoda, A. E., Marinov, B. S., Paucek, P., Costa, A. D. T., Grigoriev, S. M., Skarga, Y. Y., and Garlid, K. D. (2004) J. Biol. Chem. 279, $32562-32568$. 


\section{APPENDIX A: Mouse heart mitochondria isolation protocol}

\section{Solutions}

\section{Buffer $A$}

Sucrose

HEPES $\mathrm{pH} 7.2$

EGTA

BSA

$$
\begin{array}{r}
250 \mathrm{mM} \\
10 \mathrm{mM} \\
5 \mathrm{mM}
\end{array}
$$

$5 \mathrm{mg} / \mathrm{mL}$

\section{Buffer B}

Sucrose

$250 \mathrm{mM}$

HEPES pH $7.2 \quad 10 \mathrm{mM}$

EGTA $\quad 5 \mathrm{mM}$

[i.e. Buffer A without BSA]

\section{Procedure}

1. Anesthetize 2-3 mice with carbon dioxide ( $30 \mathrm{sec})$

2. Quickly remove heart(s) and place in a $20 \mathrm{~mL}$ beaker, on ice, filled with ice-cold Buffer B.

3. Using a squeezing action, manually remove as much blood as possible. Decant off the bloody buffer. $(\sim 15 \mathrm{sec})$

4. Add $10-15 \mathrm{~mL}$ of Buffer B supplemented with $1 \mathrm{mg} / \mathrm{mL}$ protease (Nagarse protease Sigma Type XXIV) and cut into very small pieces with a sharp scissor. (30$60 \mathrm{sec})$

5. Pour the diced suspension into a $50 \mathrm{~mL}$, ice-jacketed Potter-Elvegen tissue grinder with Teflon pestle, add $30-40 \mathrm{~mL}$ ice-cold Buffer $\mathrm{A}$ and homogenize at moderate speed (75\% of max). Usually 5-6 strokes are enough for a good homogenization. NOTE: Additional strokes will not necessarily increase protein yield, but certainly will increase the time of isolation and thus mitochondria exposure to protease, although Buffer A contains $0.5 \%$ BSA. $(30-60 \mathrm{sec})$ 
6. Pour the homogenate into two (2) pre-cooled $50 \mathrm{~mL}$ centrifuge tubes and centrifuge 3 minutes $\times 1500 \mathrm{~g}$.

7. Decant the supernatant into two, clean, pre-chilled $50 \mathrm{~mL}$ centrifuge tubes and centrifuge 5 minutes $\times 10,000 \mathrm{~g}$.

8. Discard the supernatants and resuspend each of the pellets in $\sim 0.5 \mathrm{~mL}$ of Buffer B using a pipetor to gently "wash" the pellets into homogeneous suspension. Combine all suspensions into one (1) $50 \mathrm{~mL}$ centrifuge tube, fill with Buffer $\mathrm{B}$, and centrifuge 3 minutes $\times 2300 \mathrm{~g}$.

9. Carefully decant the supernatant (containing the mitochondrial fraction) into a clean, pre-chilled $50 \mathrm{~mL}$ centrifuge tube. Discard the "fluffy" pellet that results from this low-speed spin.

10. Centrifuge the supernatant for 5 minutes $\times 10,000 \mathrm{~g}$.

11. Pour off (discard) the supernatant, and resuspend the pellet in $\sim 150$ to $200 \mu \mathrm{L}$ of Buffer B (see Step 8, above).

12. Alternatively, the centrifugation times can be cut to 3-5-3-5 min, respectively 